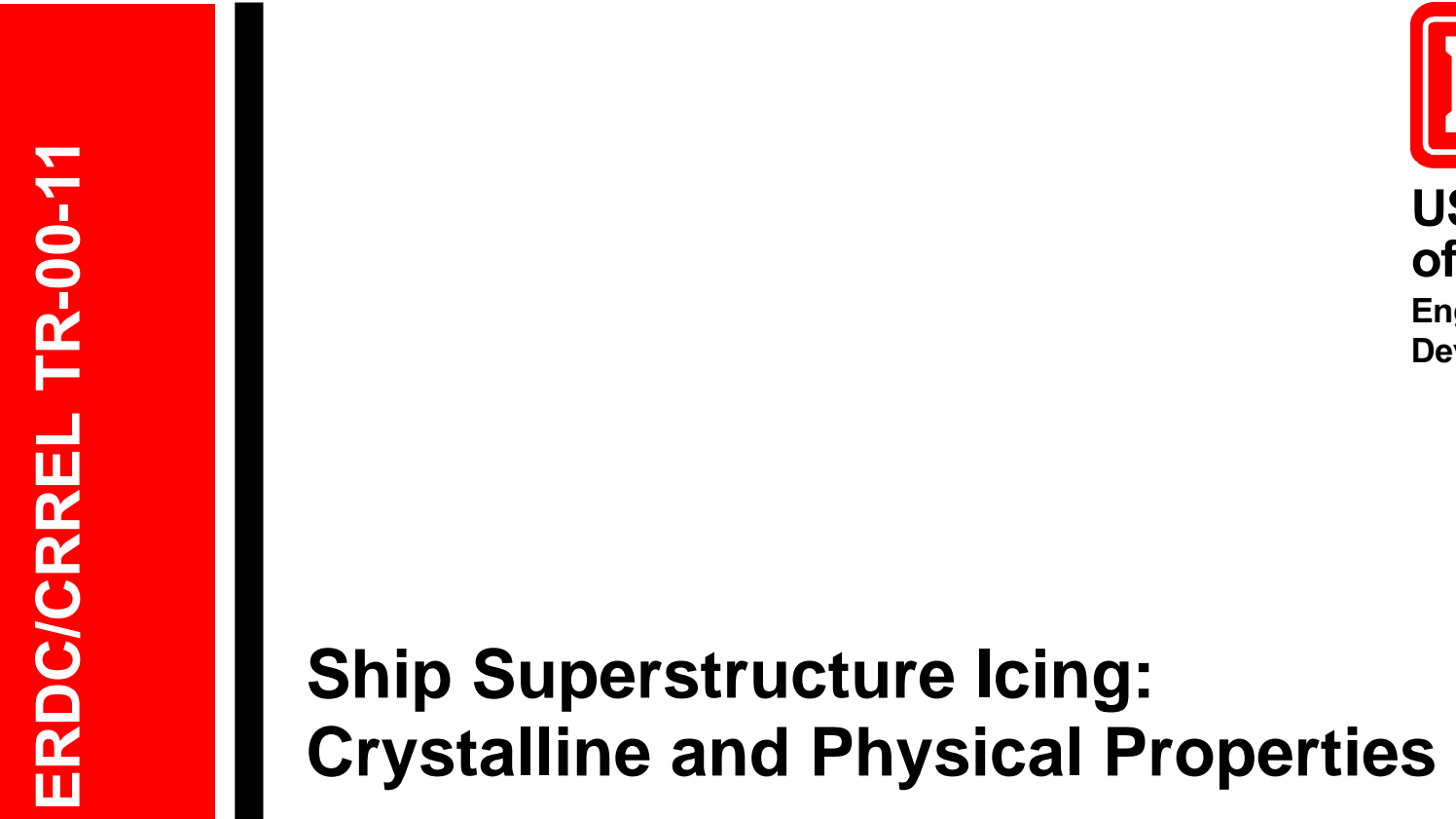

Charles C. Ryerson and Anthony J. Gow

August 2000

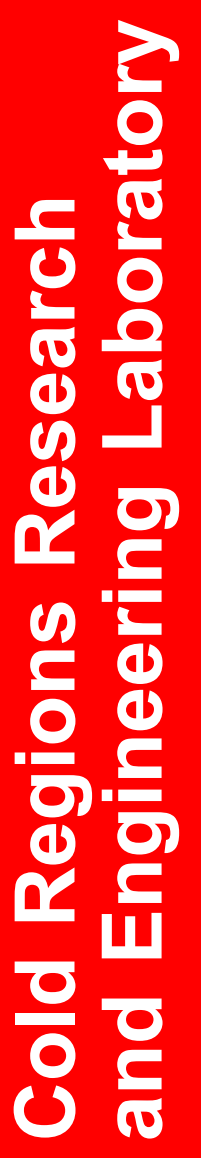


Abstract: In February and March 1990, measurements were made of superstructure ice on a United States Coast Guard cutter in the Bering Sea. Ice samples were removed from bulkheads, decks, and icicles during two icing events. Ice crystal measurements included crystal size, shape, orientation, brine pocket location, size and shape, internal layering, and air bubble sizes. Ice property measurements included salinity, density, and temperature, with computed estimates of air and brine volume. Texturally, accreted ice resembled frazil ice that forms from the consolidation of freely nucleated ice crystals in sea water. This resemblance is also reflected in bulk salinities, ranging from 7 to $24 \%$. The crystalline structure of accreted ice ranged from rounded to polygonal. Generally, rounded crystals would be expected for ice formed from sea spray droplets. The occurrence of polygonal crystals is attributed to thermally driven modification after deposition. No trend towards reorientation of crystallographic c-axes in either freshly accreted or thermally modified ice was observed. Mean crystal sizes ranged from 0.56 to $1.15 \mathrm{~mm}$, with even larger crystals in icicles. Ice salinity averaged about $12 \%$ on bulkheads and about $21 \%$ on decks. Ice densities ranged from 0.69 to $0.92 \mathrm{Mg} \mathrm{m}^{-3}$ and were generally higher on decks. Bulkhead ice had larger computed total porosity and air volume, and lower brine volume, than deck ice. Samples taken from decks and bulkheads generally compared well with Russian and Japanese measurements.

COVER:

Fishing trawler in sea smoke, Bering Sea, March, 1990. Forecastle, wheelhouse roof, and rigging are covered with superstructure ice created from bow spray.

\footnotetext{
tion Center:

DTIC-BR SUITE 0944

8725 JOHN J KINGMAN RD

FT BELVOIR VA 22060-6218

Telephone (800) 225-3842

E-mail help@dtic.mil msorders@dtic.mil

WWW http://www.dtic.mil/
}

How to get copies of CRREL technical publications:

Department of Defense personnel and contractors may order reports through the Defense Technical Informa-

All others may order reports through the National Technical Information Service:

NTIS

5285 PORT ROYAL RD

SPRINGFIELD VA 22161

Telephone (703) 487-4650

E-mail_orders@ntis.fedworld.gov

WWW http://www.ntis.gov/index.html

A complete list of all CRREL technical publications is available from USACRREL (CEERD-IM-HL)

72 LYME RD

HANOVER NH 03755-1290

Telephone (603) 646-4338

E-mail_erhoff@crrel.usace.army.mil

For information on all aspects of the Cold Regions Research and Engineering Laboratory, visit our World Wide Web site: 


\section{Technical Report ERDC/CRREL TR-00-11}

\section{Ship Superstructure lcing: Crystalline and Physical Properties}

Charles C. Ryerson and Anthony J. Gow

August 2000 


\section{PREFACE}

This report was prepared by Dr. Charles C. Ryerson, Research Physical Scientist, and Dr. Anthony J. Gow, Geologist, Snow and Ice Division, U.S. Army Engineer Research and Development Center, Cold Regions Research and Engineering Laboratory. Funding was provided by the U.S. Navy Office of Naval Technology and the Office of the Chief of Engineers, under Work Item 001Z2N, Structure and Properties of Saline Spray Ice.

The authors thank D. Meese and W. Tucker III, both of CRREL, for their constructive reviews of this report. In addition, the crew of the U.S. Coast Guard Cutter Midgett and LCDR P. Longo (ret. U.S. Navy) provided valuable assistance during and after the cruise.

The contents of this report are not to be used for advertising or promotional purposes. Citation of brand names does not constitute an official endorsement or approval of the use of such commercial products. 


\section{CONTENTS}



\section{ILLUSTRATIONS}

\section{Figure}

1. Schematic of ship superstructure icing processes ........................................... 2

2. Mass limited, thermally limited, and maximum ice accretion zones observed on a fishing trawler in the Bering Sea, March 1990 ............................................. 2

3. Deck spray created from water escaping over deck edge and through scuppers

4. Spume fountains on the port side of USCGC Midgett, a secondary source

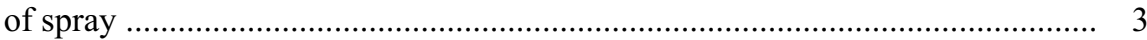

5. USCGC Midgett ............................................................................

6. Track of USCGC Midgett in the Bering Sea during icing events, February and March 1990 
7. Air temperature and sampling times during February and March 1990 ice-accretion events in the Bering Sea

8. Schematic of ice sample locations on the USCGC Midgett ............................ 7

9. Ice samples in freezer bag, and thermistor for measurement of in-situ ice temperature

10. Thin sections of ice sampled during the March icing event from a bulkhead and an icicle, illustrating grains encircled by large channelized networks filled with brine

11. Sample F3, taken from the face of the forward bulkhead and about $0.5 \mathrm{~m}$ above the deck surface.

12. Sample F4, taken from the forward bulkhead on the main deck

13. Sample F5, taken about $1.5 \mathrm{~m}$ above the deck surface on the face of the forward bulkhead

14. Sample F7, taken from the forward face of the 5-in. gun mount ...................... 18

15. Sample F8, taken $0.9 \mathrm{~m}$ above the deck on the forward face of the 5 -in. gun mount under the barrel.

16. Sample F9, taken from the DTMB ice panel on the starboard forward bulkhead

17. Sample F1, taken from the main deck during the February icing event ............. 21

18. Sample F2, taken from the deck, $25 \mathrm{~cm}$ forward of the bulkhead ...................... 22

19. Sample F6, taken from the ice accretion panel on the main deck hatch ............ 23

20. Sample M3, taken from beneath the barrel of the 5-in. gun .............................. 24

21. Sample M5, a vertical sample taken from the front of the 5-in. gun housing

22. Sample M6, removed from the port face of the 5-in. gun mount ....................... 25

23. Sample M9, taken from the port bulkhead of the 5-in. gun housing, $1.8 \mathrm{~m}$ above the deck surface

24. Sample M10, taken from the port bulkhead of the 5-in. gun housing, approximately $1 \mathrm{~m}$ above the deck

25. Sample M14, taken about $1.5 \mathrm{~m}$ above the deck surface from the front

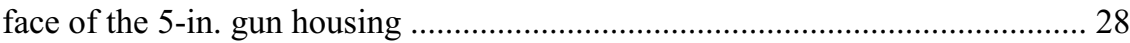

26. Sample M8, taken from the deck, $2-3 \mathrm{~m}$ to the port of the 5 -in. gun base ........ 28

27. Sample M13, taken from the deck in warm weather, near $-3^{\circ} \mathrm{C}$....................... 29

28. Vertical section of icicle, sample M11, photographed between crossed polarizers

29. Sample M11, taken from an icicle removed from the left end of the upper lifeline shown in Figure 29a

30. Sample M12, taken from icicles hanging from the port side base of the 5 -in. gun housing

\section{TABLES}

Table

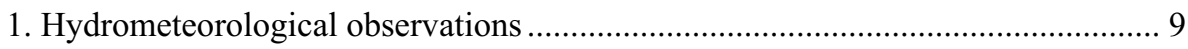

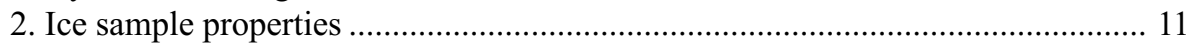

3. Crystal and bubble size measurements ............................................................ 14 


\title{
Ship Superstructure Icing: Crystalline and Physical Properties
}

\author{
CHARLES C. RYERSON AND ANTHONY J. GOW
}

\section{INTRODUCTION}

\section{Background}

Ice grows on ship superstructure components as a result of precipitation of saline spray from the ocean surface in winter seas. A potentially serious problem, superstructure icing reduces ship sea-keeping ability and hinders deck operations. Resulting largely from spray lofted from the sea surface by bow-wave collisions, spray drops are carried by the relative wind, the resultant of true wind speed and direction and ship speed and direction, over the ship. The rate of spray freezing and subsequent ice growth is a function of both the spray rate at every location on the ship, and the rate of latent and sensible heat removal at these locations.

Spray ice accretion rates vary considerably with location on a ship (Ackley 1985). Ice accretion rates are determined by the balance of heat delivery by spray, both sensible and latent, and atmospheric heat removal processes. Figure 1 illustrates three icing zones that often occur on all sizes of ships. The maximum accretion zone is where spray delivery matches the atmosphere's ability to remove sensible and latent heat from impinged water at a sufficient rate for all spray to freeze (although some spray remains trapped as brine within the ice). Maximum accretion may take place at bow locations maximally exposed to the wind, such as at the top of the bow and windlass located on the forecastle of the fishing trawler shown in Figure 2. However, during heavy spraying, the most ice is likely to accrete amidships, where the spray flux is smaller and the rate of heat removal by the atmosphere is still large (Fig. 1). This is demonstrated by the wheelhouse roof and areas immediately aft of the wheelhouse on the trawler (Fig. 2). Maximum accretion is likely to occur higher on the superstructure in forward areas, as spray flux normally decreases with distance aft of the bow, and with height above the deck.

Thermally limited accretion (Fig. 1) takes place where the spray water delivered exceeds the atmosphere's ability to remove its sensible and latent heat. Thus, ice accretion rates are smaller than water delivery suggests. Large spray fluxes, and thus thermally limited accretion, are normally only found on the bow areas of large ships, even though large volumes of spray can reach farther aft on smaller ships. Figure 2 illustrates a situation where thermally limited accretion is restricted primarily to portions of the bow, the forecastle deck, and the forward bulkhead of the trawler.

Mass limited accretion generally occurs aft and above the maximum accretion zone because spray generally decreases with distance aft of the bow and above the main deck (Fig. 1). The mass limited accretion zone is characterized by water delivery rates, and, thus, sensible and latent heat delivery rates, that are smaller than the atmosphere's ability to remove the heat. Thus, all of the spray (except brine concentrated within brine pockets) freezes and ice accretion is limited by available spray. It does not reach its potential thickness as determined by the atmosphere's ability to remove heat. Mass limited accretion is most dramatically illustrated by the upper portions of the twin masts on the trawler's fantail, where ice thickness decreases with height (Fig. 2).

The three superstructure icing zones are dynamic, with the amount of superstructure covered by each changing as spray delivery rates and patterns, and 


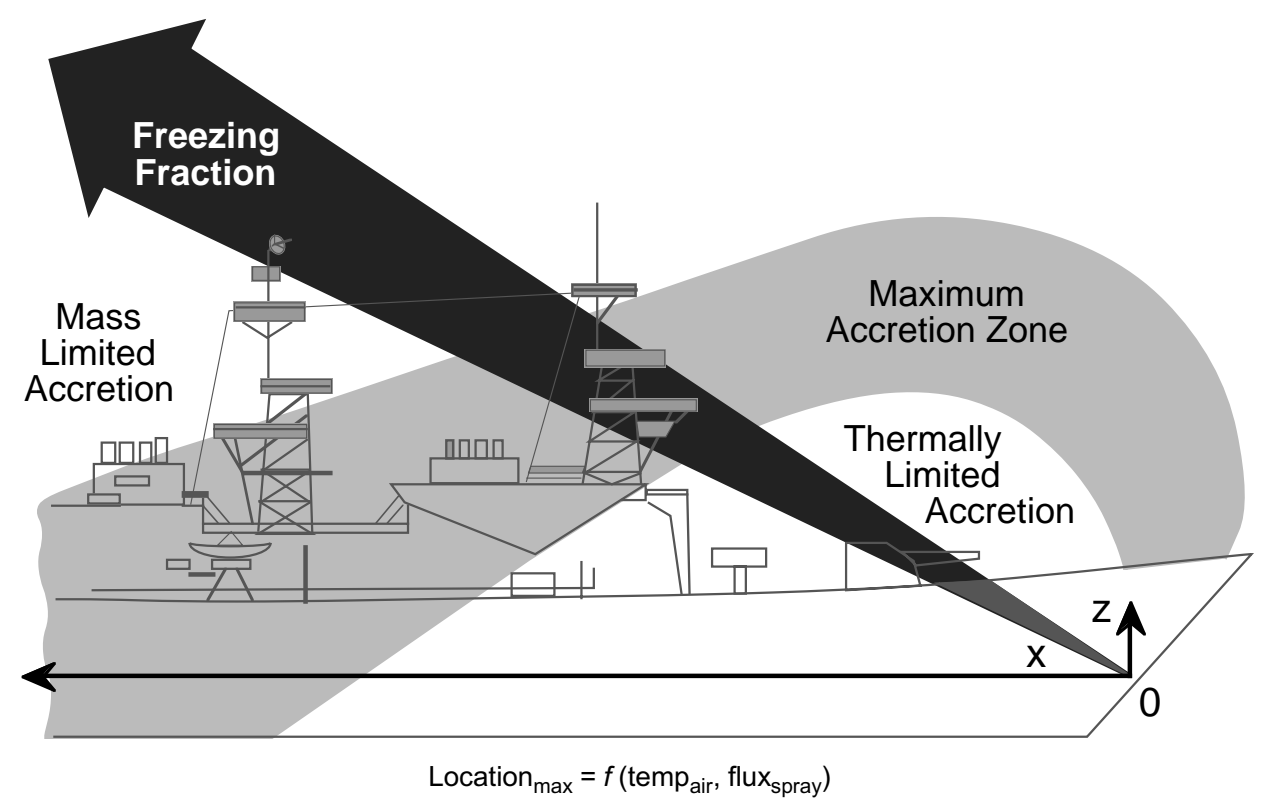

Figure 1. Schematic of ship superstructure icing processes. Three principal icing zones are indicated, with the location of maximum ice accretion (Location $_{\max }$ ) largely a function of spray flux (flux spray ) and air temperature (tempair).

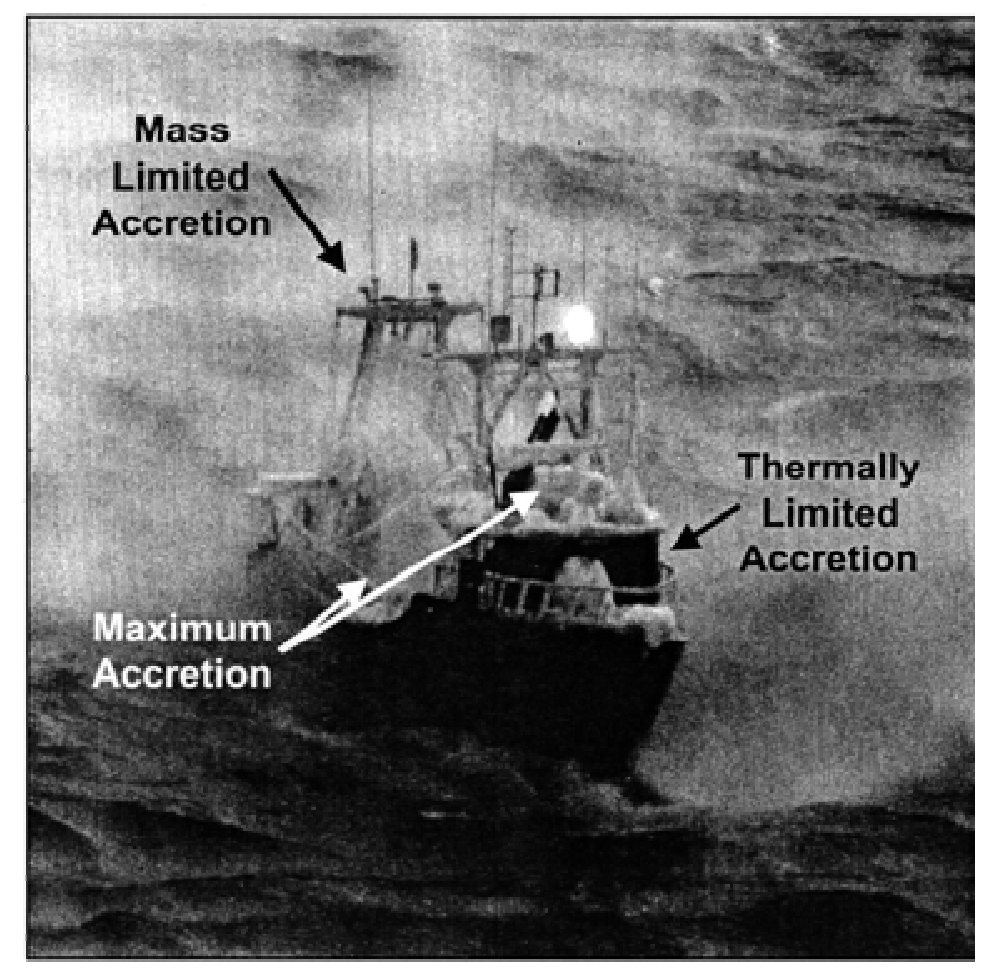

Figure 2. Mass limited, thermally limited, and maximum ice accretion zones observed on a fishing trawler in the Bering Sea, March 1990. 
atmospheric conditions such as relative wind speed and direction, change. Thus, it is conceivable that ice may be growing on some portions of the superstructure, while on other areas it may be eroding (Ryerson 1995). In addition, depending upon ship size, spray delivery rates, and atmospheric conditions, only one, two, or all three of the zones may be found at any one time on the ship. Often, however, thermally limited accretion occurs in the bow area, transitioning to maximum, and mass limited, accretion zones at higher levels and farther aft. The freezing fraction, as defined by the portion of impinging spray water that remains trapped in ice on the superstructure, also increases with distance aft of the bow and with height above the water (Fig. 1).

The size and design of a ship also have other effects upon the rate of superstructure spraying during icing conditions, and the subsequent growth of topside ice. Smaller vessels are immersed with spray more frequently than larger ships because of their lower freeboard and greater heave frequency. Also, bow spray clouds are more likely to cover the entire superstructure of a small ship with a large spray flux. Larger vessels create spray less frequently because of their smaller heave frequency and rate, and larger freeboard. In addition, bow spray clouds are less likely to cover all of a large vessel. Therefore, only a portion of the entire ship is likely to ice heavily, resulting in less rapid overall accretion rates and less threatening accretions. Finally, the shape of the vessel's hull determines the amount of spray lofted over the superstructure. Ships with greater freeboard in the bow area and greater bow rake or flare will tend to deflect spray away from themselves, and reduce entrainment of drops into the relative wind (Sapone 1990).

Though bow spray generates the most liquid water content, secondary spray also results when water accumulated on decks drains over the edge or through scuppers. It also results from spume fountains. In the former situation, wind moving up the side of the flared bow entrains water draining from the decks, creating a secondary spray event that follows the primary event by a few seconds. This secondary spray event prolongs total spraying but has small liquid water content (Fig. 3).

Light spray also originates along the windward sides of ships in moderate or larger seas from interaction of the bow wave with natural waves, causing breakers and "spume fountains" (Fig. 4). Spume occurs only where the bow wave and natural waves meet, causing them to break, which happens at an increasing distance from the ship with distance aft of the bow, creating a light mist along the sides of the ship.

\section{Research cruise}

CRREL was contracted by the U.S. Navy to make

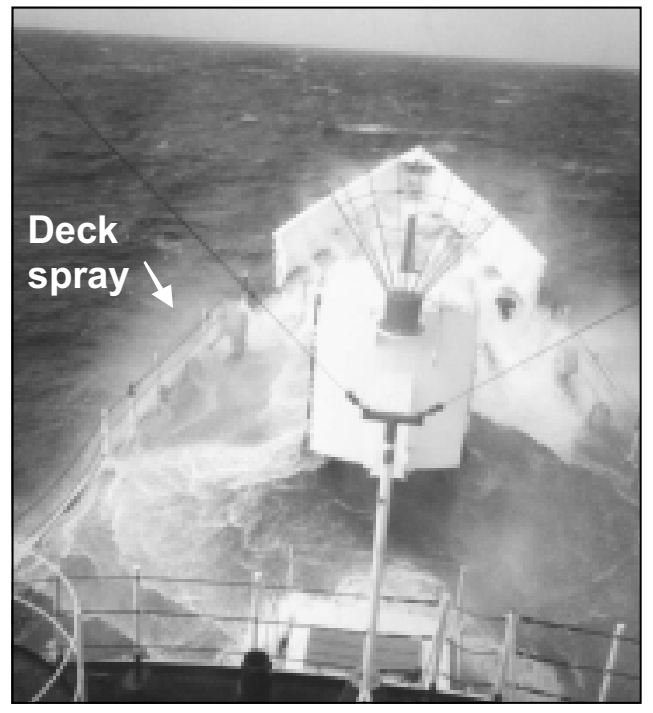

Figure 3. Deck spray created from water escaping over deck edge and through scuppers. This is a secondary source of spray causing superstructure icing.

measurements of superstructure spray and ice aboard the United States Coast Guard cutter Midgett in the Bering Sea during February and March 1990. The USCGC Midgett (Fig. 5) is not as large as a typical Navy destroyer or cruiser at $378 \mathrm{ft}(115 \mathrm{~m})$ and 2980 tons (2703 tonnes) displacement, but our measurements were intended to characterize spray and ice conditions that might occur on a U.S. Navy ship. The size and seakeeping ability of the cutter were certainly more repre-

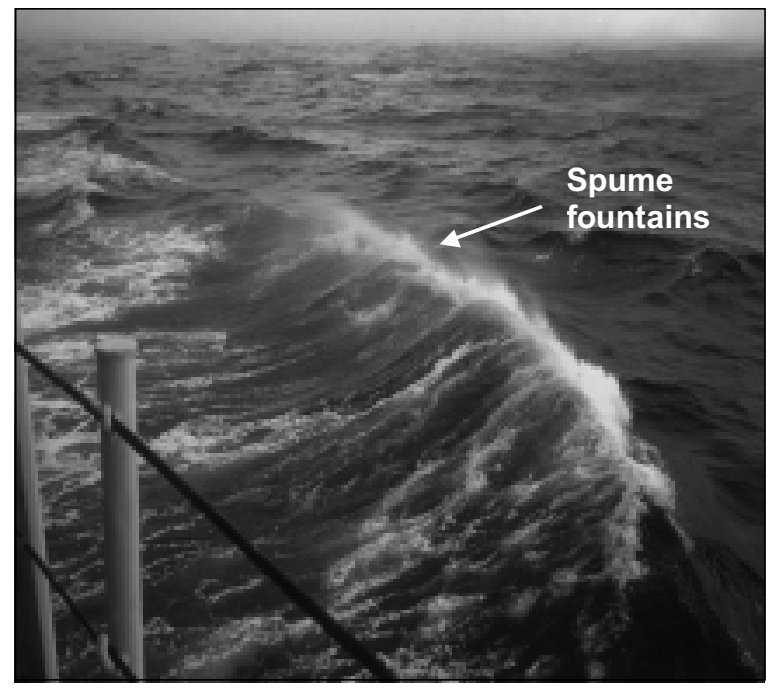

Figure 4. Spume fountains on the port side of USCGC Midgett, a secondary source of spray. 


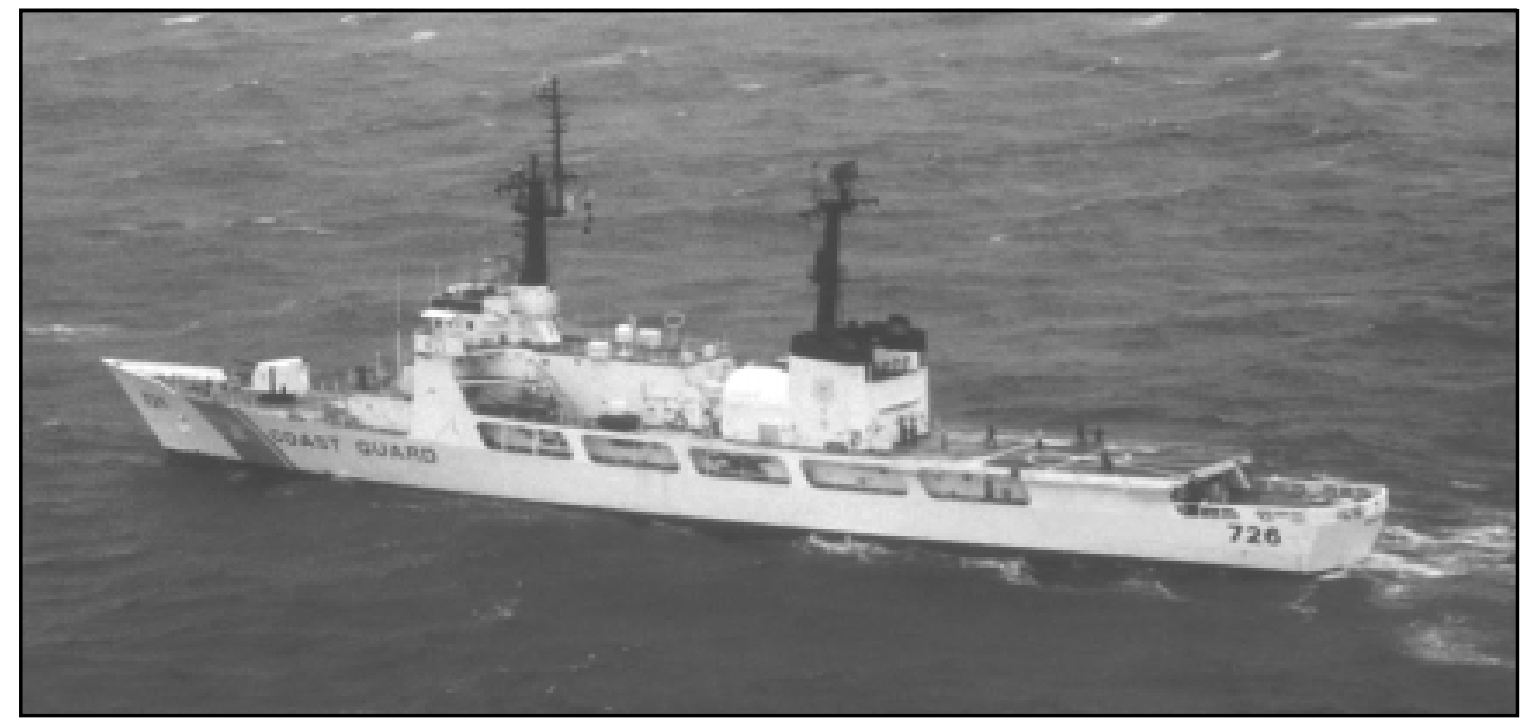

Figure 5. USCGC Midgett.

sentative of a Navy ship than of a typical fishing trawler.

The monitoring cruise (Fig. 6) in the Bering Sea began 5 February 1990, at Alameda, California, and reached Kodiak, Alaska, by 16 February (Ryerson and Longo 1992). After leaving Kodiak, the cutter entered the Bering Sea through Unimak Pass and remained there until the research team disembarked at Adak, Alaska, on 15 March (Ryerson and Longo 1992). The cutter's primary mission was not research, but enforcement of
Maritime Law and to provide search and rescue services as required. Therefore, members of the research team were guests of the ship and had no control over ship operations or cruise track for making scientific measurements. Nearly all spray and ice measurements were made opportunistically. The mission took the ship into areas where potentially severe weather could cause icing, and where there was significant spray (Thomas and Lee 1987, Ryerson et al. 1991).

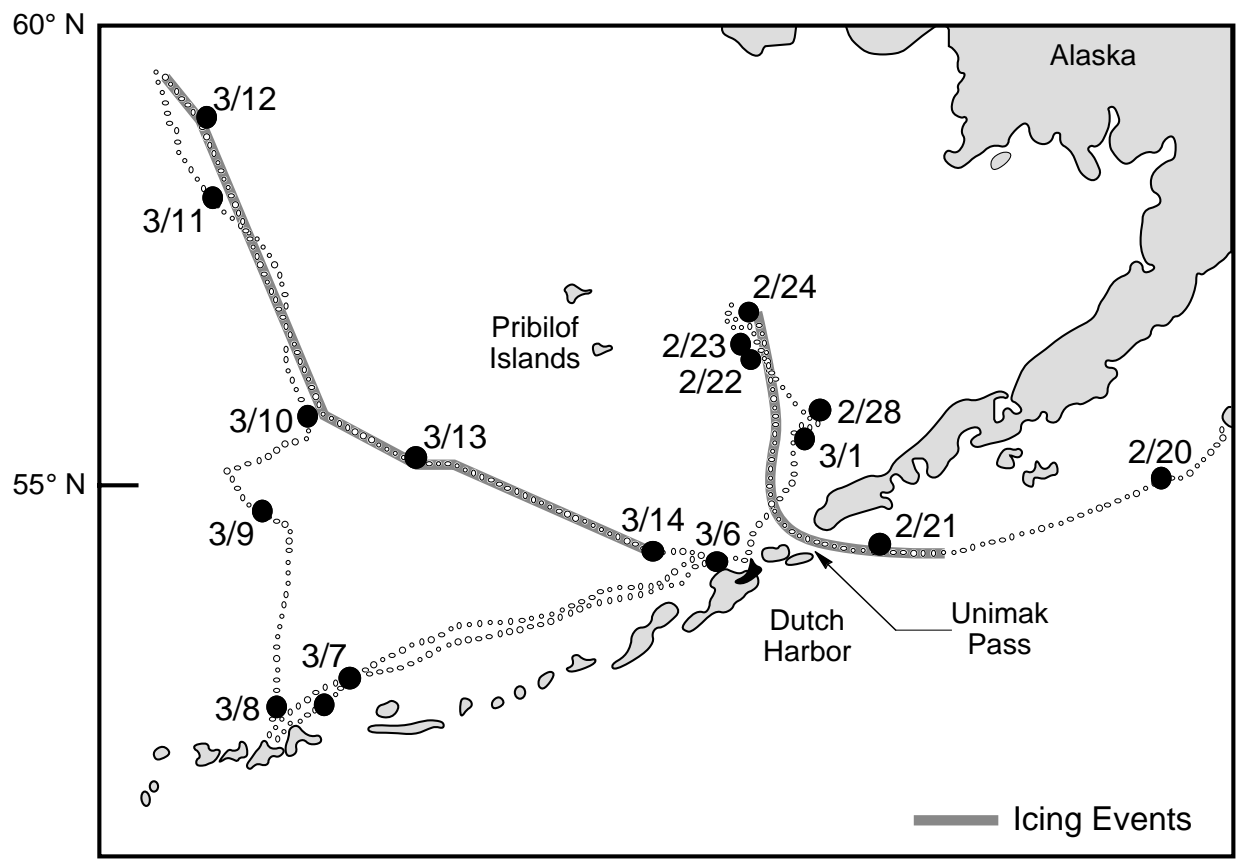

Figure 6. Track of USCGC Midgett in the Bering Sea during icing events, February and March 1990. 


\section{PURPOSE OF RESEARCH}

Measurements were made aboard ship to characterize superstructure spray and ice accretion. Weather, sea, and ship operating conditions were measured by the ship's personnel, and sea water temperature and salinity were measured by the ship's crew and the CRREL research team (Ryerson and Longo 1992).

Though the research cruise continued for about 40 days, only a few days of spray and ice data were recorded because of unsuitable weather and ship operations. Seas were frequently calm, temperatures were typically higher than the freezing temperature of sea water, and the ship was often stationary or moving slowly and producing no spray because patrol duties required the launch and retrieval of small boats and a helicopter. Nevertheless, sufficient data were collected to characterize spray and ice.

A previous report (Ryerson 1995) gives detailed information on bow spray duration, drop concentration, drop size distribution and liquid water content, and the general ice accretion and ablation conditions, as well as thickness distribution. This report characterizes the physical structure and crystalline properties of ice sampled from the ship superstructure, and expands upon observations made by us in an abbreviated paper (Ryerson and Gow, in press).

\section{ICE PHYSICAL AND CRYSTALLINE PROPERTIES}

In the 1960s, the Soviets measured the physical properties of spray-deposited ice on medium size fishing trawlers (Panov 1972, Golubev 1972, Smirnov 1972, Kultashev et al. 1972). Measurements were also made by Japanese researchers on ships ranging in size from trawlers to patrol boats (Ono 1968, Tabata et al. 1963, Iwata 1975). Supplementary work has also been done in saline wind tunnels, especially to measure salinity, brine volume, and porosity (Makkonen 1987, Gates et al. 1986), and with models to simulate ice accretion amount with location on the superstructure, and icicles (Lozowski and Szilder, in press). Measurements have not been made on ships in the Western Hemisphere, and none have been made on large ships except by CRREL (Ryerson 1995). Ice properties such as thickness and density affect the mass of ice accreted on decks and bulkheads. In addition, crystal structure, as well as physical properties, provides information about the history of the ice and its depositional environment.

The properties of saline ice formed by direct freezing of ocean water, and its evolution with time and location, are reasonably well understood (Weeks and
Ackley 1982, Mellor 1983) compared to spray-accreted saline ice. Saline spray ice freezes rapidly compared to floating sea ice, forms on vertical surfaces in addition to horizontal surfaces, and is periodically flushed and dried as more spray lofts over the bow and brine drains from ice at higher locations on the superstructure. This unique energy and mass environment for saline ice growth and evolution affects the mass of ice at various locations on the ship, and its strength, physical, and crystalline properties.

\section{METHODOLOGY}

In two icing events aboard the cutter, 23 ice samples were removed from decks, bulkheads, the gun mount, and lifelines (Ryerson and Longo 1992, Ryerson 1995). The first icing event occurred from 22-25 February, and the second from 10-14 March. Ice samples were removed from decks and bulkheads on 24 February and 12 and 13 March (three times on the latter date) as indicated in Figure 7. As shown in Figure 8, all samples were taken on and around the forecastle because insufficient ice accreted elsewhere.

Samples were removed, using a putty knife, in complete sections from decks, bulkheads, hatches, and cables of painted steel, painted aluminum, nonskid, or polypropylene. They were immediately placed in clear plastic freezer bags and sealed to prevent draining brine from escaping. In addition, in-situ ice temperatures were measured (Fig. 9). Though many samples appeared to be nearly saturated on decks, no water freely ran from them as they were removed. Samples removed from bulkheads were always dry at the ice/substrate interface.

Samples were kept on deck in freezer bags during the duration of each 30- to 60-minute sampling excursion. They were then moved in an insulated container to the officer's galley refrigerator freezer compartment, approximately amidships. The temperature of the freezer compartment was approximately $-18^{\circ} \mathrm{C}$. Within minutes to a few hours, samples were moved again in an insulated container to the ship's main food locker, also at $-18^{\circ} \mathrm{C}$ (Ryerson and Longo 1992). The samples remained in the food locker within picnic coolers until May 1990.

Immediately upon the ship's return to Alameda, California, at the end of the cruise, the coolers of bagged ice were packed with dry ice. The still-bagged ice samples were kept sealed and separated from the dry ice by layers of cardboard. The coolers were then airshipped to CRREL within 24-hours and placed in cold storage. The ice was stored in coldrooms at temperatures of -12 to $-30^{\circ} \mathrm{C}$ for 6 to 7 months before we made 


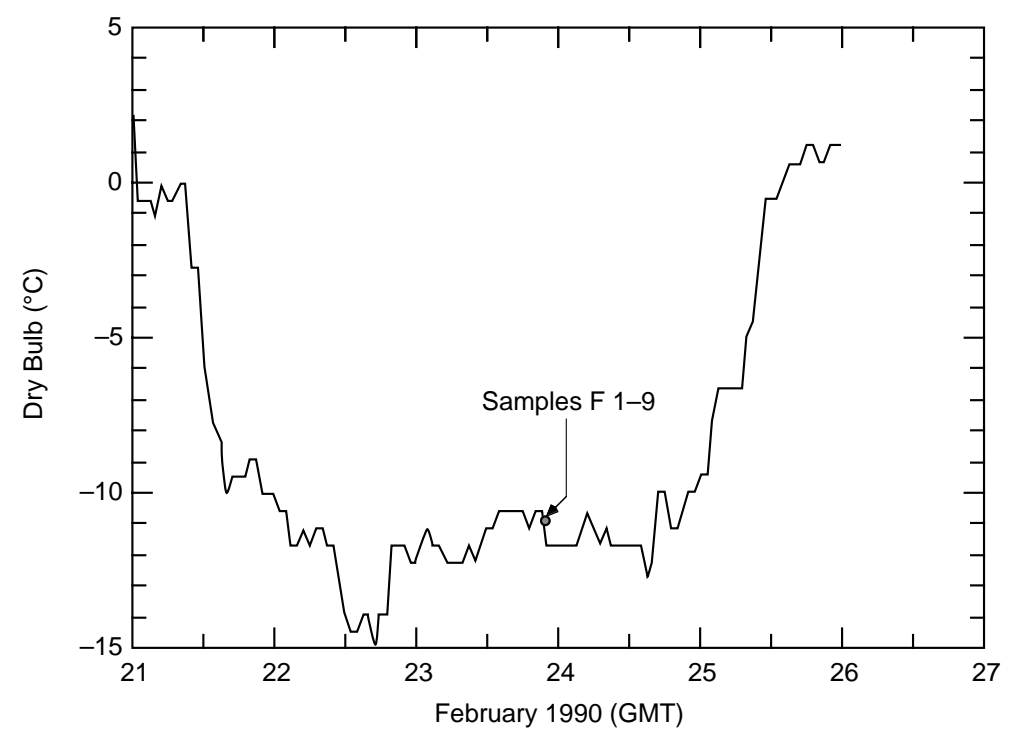

a. February icing event.

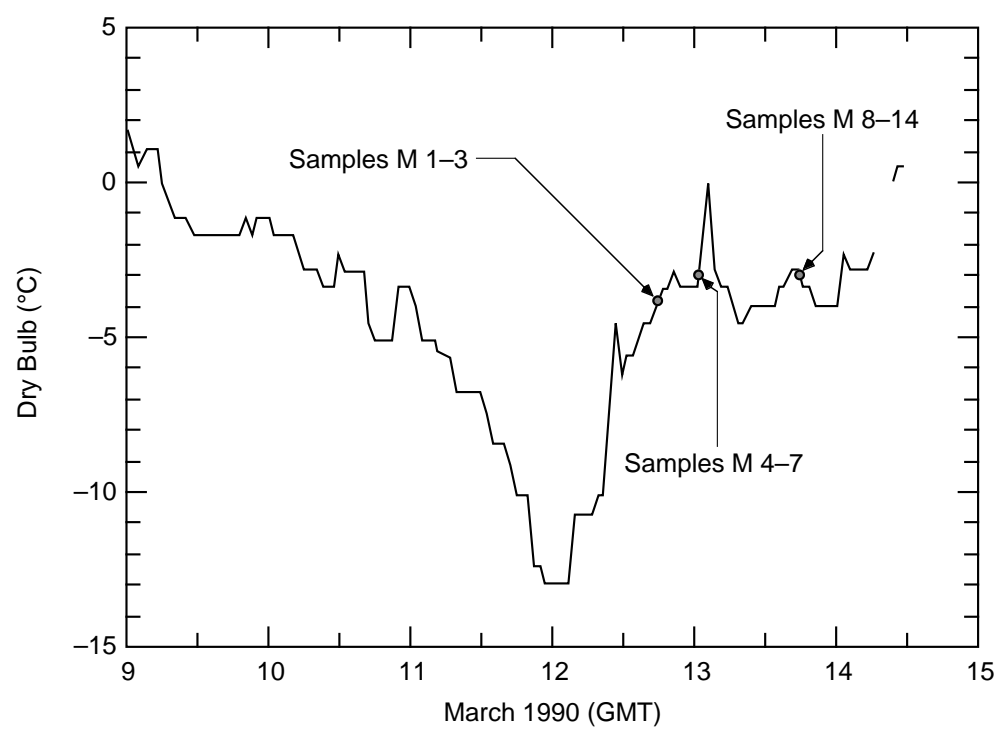

b. March icing event.

Figure 7. Air temperature and sampling times during February and March 1990 ice-accretion events in the Bering Sea. Sample numbers refer to Figure 8 and Tables 2 and 3. During each sampling period, all samples were collected within about 30-60 minutes of one another. 

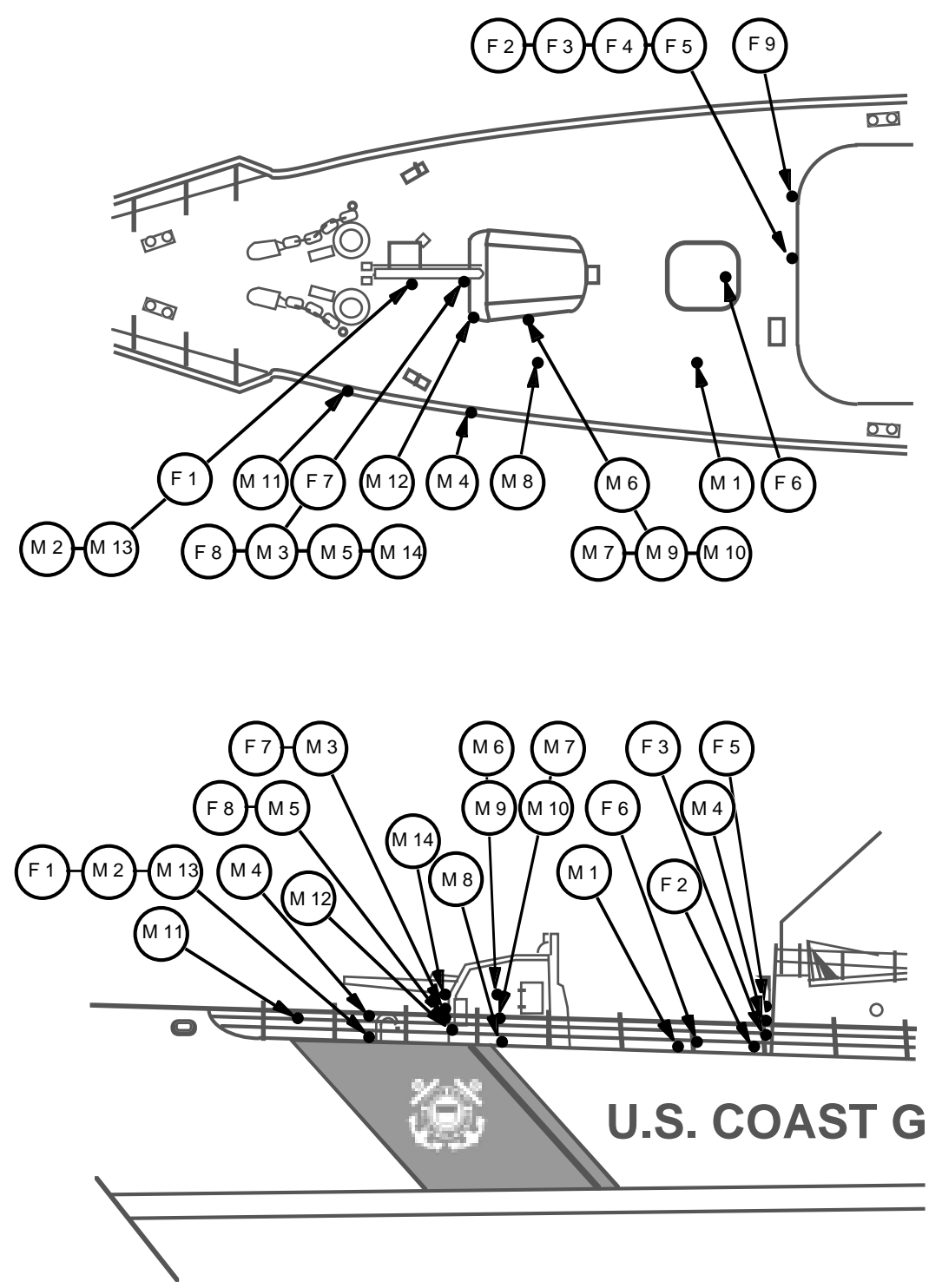

Figure 8. Schematic of ice sample locations on the USCGC Midgett. Letters refer to the sample month ( $F=$ February, $M=$ March), and numbers denote sample number within the month (see Tables 2 and 3). 




Figure 9. Ice samples in freezer bag, and thermistor for measurement of in-situ ice temperature.

the initial density and salinity measurements and initial observations of the crystal structure in thin sections. Samples were prepared and analyzed in coldrooms at temperatures ranging from -10 to $-18^{\circ} \mathrm{C}$. In 1998 , thin sections of the crystal structure were reexamined, mainly to determine the sizes of crystals and inclusions and their relationships to one another.

Measurements of saline ice properties and structure are best made immediately after sampling to minimize brine drainage. Temperature changes or communication with the atmosphere can also cause changes during transport and storage (Weeks and Ackley 1982). However, careful packing and storage can minimize problems and preserve the ice sufficiently for useful analyses at a later time.

\section{Hydrometeorological observations}

Though there were two superstructure icing events during the USCGC Midgett research cruise, air temperature actually dropped below the freezing temperature of sea water $\left(-2.2^{\circ} \mathrm{C}\right)$ for five periods during the cruise. However, only during two of these periods was there measurable bow spray icing, both during the Bering Sea portion of the research cruise.

The weather during the February icing event was considerably colder than that during the March event, averaging $-10.2^{\circ} \mathrm{C}$ vs. $-5.6^{\circ} \mathrm{C}$ (Table 1 , Fig. 7). Minimum and maximum temperatures are both higher in the March event, and temperatures lingered near freezing for at least $50 \%$ of the event. By contrast, tempera- tures in the February event dropped below $-9.5^{\circ} \mathrm{C}$ and remained there for several days. In both events wet bulb temperatures always remained within a few degrees below the dry bulb temperature, keeping relative humidity high. In 117 cases of trawler icing along the east coast of North America (Ryerson 1991), air temperatures averaged $-8.1^{\circ} \mathrm{C}$, with $67 \%$ of all cases occurring between temperatures of -3.5 and $-12.6^{\circ} \mathrm{C}$. Studies by the Soviets indicate that icing rarely happens at air temperatures above $-3.0^{\circ} \mathrm{C}$, and in most cases occurs between temperatures of -3.4 and $-12.6^{\circ} \mathrm{C}$. Japanese research has found icing to be most severe in air temperatures between -6.0 and $-8.1^{\circ} \mathrm{C}$ (Ono 1968). Both of the icing events fell well within the most common temperatures observed by other researchers during superstructure icing events.

Mean true wind speeds were approximately the same in both icing events, though the range of speeds was somewhat greater in February (Table 1). True wind directions in both events started in the east and northeast, and rapidly backed to the north-northwest, pulling cold air from the Alaskan mainland and an extensive sea ice cover. Warming southerly winds ended both events. Trawler icing was found to be most severe when winds were directly off of a large nearby land mass, a large source of cold air (Ryerson 1991).

Ship speeds ranged up to $8.7 \mathrm{~m} \mathrm{~s}^{-1}$ in the two events, but averaged only about $3.0 \mathrm{~m} \mathrm{~s}^{-1}$ in the February event, and $6.2 \mathrm{~m} \mathrm{~s}^{-1}$ in the March event (Table 1). Average ship speeds are not very meaningful, however, because 


\begin{tabular}{|c|c|c|c|c|c|}
\hline \multicolumn{6}{|c|}{ Table 1. Hydrometeorological observations. } \\
\hline Variable & Mean & StdD & Min & Max & $N^{*}$ \\
\hline \multicolumn{6}{|l|}{ February 1990} \\
\hline Dry bulb $\left({ }^{\circ} \mathrm{C}\right)$ & -10.2 & 2.3 & -14.0 & -5.0 & 40 \\
\hline Wet bulb $\left({ }^{\circ} \mathrm{C}\right)$ & -10.9 & 2.2 & -15.1 & -6.2 & 38 \\
\hline Rel. wind vel. $\left(\mathrm{m} \mathrm{s}^{-1}\right)$ & 12.3 & 6.5 & 2.1 & 24.2 & 40 \\
\hline Rel. wind dir. $\left({ }^{\circ}\right)$ & 174.9 & 79.5 & 21.2 & 353.8 & 40 \\
\hline Wind direction $\left({ }^{\circ}\right)$ & 90.3 & 107.4 & 1.0 & 350.0 & 40 \\
\hline Wind speed $\left(\mathrm{m} \mathrm{s}^{-1}\right)$ & 11.1 & 6.2 & 1.5 & 20.1 & 40 \\
\hline Rel. wave dir. $\left(^{\circ}\right)$ & 169.9 & 118.4 & 3.0 & 359.0 & 15 \\
\hline Rel. swell dir. $\left({ }^{\circ}\right)$ & 118.7 & 93.1 & 9.0 & 279.0 & 16 \\
\hline Course $\left(^{\circ}\right)$ & 127.2 & 89.9 & 1.0 & 321.0 & 40 \\
\hline Ship speed $\left(\mathrm{m} \mathrm{s}^{-1}\right)$ & 3.0 & 2.7 & 0.3 & 8.7 & 40 \\
\hline Air pressure $(\mathrm{kPa})$ & 101.5 & 0.1 & 99.4 & 102.0 & 40 \\
\hline Wave direction $\left({ }^{\circ}\right)$ & 57.3 & 86.6 & 0.0 & 224.0 & 15 \\
\hline Wave height (m) & 1.0 & 0.5 & 0.3 & 1.8 & 15 \\
\hline Swell direction $\left({ }^{\circ}\right)$ & 41.9 & 83.2 & 0.0 & 350.0 & 16 \\
\hline Swell height $(\mathrm{m})$ & 1.6 & 0.7 & 0.6 & 2.4 & 16 \\
\hline Water temperature $\left({ }^{\circ} \mathrm{C}\right)$ & 1.8 & - & 0.2 & 3.4 & 15 \\
\hline Water salinity $(\% \circ)$ & 33.1 & - & 33.0 & 33.5 & 15 \\
\hline Beaufort wind force & 5.9 & 2.1 & 2.0 & 9.0 & 36 \\
\hline Wave + swell ht. (m) & 3.1 & 1.0 & 1.8 & 4.3 & 12 \\
\hline Wave-swell angle $\left({ }^{\circ}\right)$ & 40.2 & 97.7 & 6.0 & 350.0 & 12 \\
\hline \multicolumn{6}{|l|}{ March 1990} \\
\hline Dry bulb $\left({ }^{\circ} \mathrm{C}\right)$ & -5.6 & 3.7 & -12.9 & 0.6 & 162 \\
\hline Wet bulb $\left({ }^{\circ} \mathrm{C}\right)$ & -6.0 & 3.7 & -12.9 & 0.6 & 162 \\
\hline Rel. wind vel. $\left(\mathrm{m} \mathrm{s}^{-1}\right)$ & 10.4 & 2.5 & 4.2 & 19.0 & 170 \\
\hline Rel. wind dir. $\left(^{\circ}\right)$ & 155.6 & 81.8 & 51.6 & 342.3 & 170 \\
\hline Wind direction $\left({ }^{\circ}\right)$ & 170.8 & 139.9 & 4.0 & 355.0 & 170 \\
\hline Wind speed $\left(\mathrm{m} \mathrm{s}^{-1}\right)$ & 11.3 & 3.3 & 4.1 & 18.0 & 170 \\
\hline Rel. wave dir. $\left(^{\circ}\right)$ & 201.3 & 108.6 & 19.0 & 349.0 & 69 \\
\hline Rel. swell dir. $\left({ }^{\circ}\right)$ & 183.2 & 103.2 & 9.0 & 349.0 & 94 \\
\hline Course $\left(^{\circ}\right)$ & 168.9 & 93.1 & 1.0 & 355.0 & 170 \\
\hline Ship speed $\left(\mathrm{m} \mathrm{s}^{-1}\right)$ & 6.2 & 2.5 & 0.3 & 8.2 & 170 \\
\hline Air pressure $(\mathrm{kPa})$ & 100.5 & 0.8 & 99.4 & 102.3 & 170 \\
\hline Wave direction $\left({ }^{\circ}\right)$ & 117.3 & 123.6 & 10.0 & 350.0 & 69 \\
\hline Wave height $(\mathrm{m})$ & 0.9 & 0.2 & 0.6 & 1.2 & 69 \\
\hline Swell direction $\left(^{\circ}\right)$ & 48.3 & 63.1 & 0.0 & 335.0 & 94 \\
\hline Swell height $(\mathrm{m})$ & 1.4 & 0.3 & 0.9 & 2.1 & 94 \\
\hline Water temperature $\left({ }^{\circ} \mathrm{C}\right)$ & 2.2 & - & 1.1 & 3.2 & 12 \\
\hline Water salinity $(\% \circ)$ & 34.1 & - & 33.9 & 34.4 & 12 \\
\hline Beaufort wind force & 5.2 & 1.0 & 3.0 & 8.0 & 141 \\
\hline Wave + swell ht. (m) & 2.4 & 0.6 & 1.5 & 3.4 & 69 \\
\hline Wave-swell angle $\left(^{\circ}\right)$ & 66.2 & 116.1 & 0.0 & 330.0 & 69 \\
\hline
\end{tabular}

ship heading and seaway conditions interact so strongly with ship speed to produce spray.

Relative wind speeds across the bow were computed from true wind speed, ship speed, and true wind direction (Ryerson and Longo 1992). Relative wind direction was computed at the same time, but direction is computed clockwise from the stern, instead of from the bow, to minimize mathematical errors arising from averaging wind directions. Thus, port beam winds have a direction of $90^{\circ}$, head winds a direction of $180^{\circ}$, and starboard beam winds $270^{\circ}$.

Relative wind velocities were somewhat larger in the February event, with a maximum of $24.2 \mathrm{~m} \mathrm{~s}^{-1}$ (Table 1). Relative wind directions averaged about $175^{\circ}$ in the February event, almost on the bow, but were about $156^{\circ}$ in March, $24^{\circ}$ to port. Kultashev et al. (1972) found spraying to be greatest on trawlers when winds and seas approached the ship $30-40^{\circ}$ off the bow. Japanese 
researchers found icing rates to be greatest on those parts of the ship that face the seas and winds (Tabata et al. 1963). These relative winds also produced the greatest icing, in concert with low temperatures, when velocities were greater than $10.8 \mathrm{~m} \mathrm{~s}^{-1}$ (Ono 1968). Iwata (1975) observed icing on patrol boats at relative wind speeds of 10.3 to $20.6 \mathrm{~m} \mathrm{~s}^{-1}$. Gashin observed the most intense icing on the trawler Aysberg when wind speeds were greater than $20.6 \mathrm{~m} \mathrm{~s}^{-1}$ (Borisenkov and Panov 1972). The relative winds encountered by the cutter, as measured on the Beaufort scale, averaged from Force 5 to 6 during the two events, with a maximum of Force 9 during the February icing event, and Force 8 during the March event (Table 1). According to Jorgensen (1982), Beaufort Forces 5-6 are the most common lower limits for ship icing.

Seas were generally heavier during the February icing event, with the mean and extremes being larger for wave height, swell height, and combined wave and swell height. For the two events together, however, waves averaged about $1.0 \mathrm{~m}$, with maxima of 1.2 to 1.8 $\mathrm{m}$, and swells averaged about $1.5 \mathrm{~m}$ with maxima of 2.1 to $2.4 \mathrm{~m}$ (Table 1). Combined seas reached 3.4 to $4.3 \mathrm{~m}$. Fishing trawlers suffer from icing most often in waves of about $1.5 \mathrm{~m}$ and swells of about $1.8 \mathrm{~m}$ off the east coast of North America, comparable to those measured during icing of the cutter (Ryerson 1991).

Relative wave direction and relative swell direction were computed similarly to relative wind, with $0^{\circ}$ at the stern. In general, waves and swells struck the cutter on the port side because of vagaries in the ship's track, geographic position, and weather patterns. During the February icing event, waves arrived about $10^{\circ}$ off the port bow, but swells arrived about $60^{\circ}$ off the port bow. The March event actually received waves and swells from nearly bow-on to $20^{\circ}$ to starboard (Table 1). Kultashev et al. (1972) observed maximum spraying on trawlers when winds and seas approached the ship $30-40^{\circ}$ off the bow.

Water temperature was measured at the engine coolant intakes by the quartermasters. It was also recorded by bathythermographs, and by the CRREL researchers using dipping buckets (Ryerson and Longo 1992). From these combined sources, best estimates of seawater temperature were derived (Table 1). Water temperatures averaged about $1.8^{\circ} \mathrm{C}$ during the February event, and $2.2^{\circ} \mathrm{C}$ during the March event. In a literature review, Shellard (1974) found little agreement about the importance of seawater temperature to icing rates. However, he indicates that there generally is no icing when water temperatures are above $8^{\circ} \mathrm{C}$. Lower water temperatures contribute to heavier icing, but the air temperature is the overriding factor. On trawlers off of the east coast of North America, icing was most common when sea water temperatures averaged $1.02^{\circ} \mathrm{C}$, with $67 \%$ of all cases occurring in temperatures between -1.0 and $3.0^{\circ} \mathrm{C}$ (Ryerson 1991). Jorgensen (1982) indicates that when wind speeds are high, and air temperatures are lower than $-5.0^{\circ} \mathrm{C}$, seawater temperature has a negligible effect on icing rate.

Seawater salinity was also infrequently sampled on the USCGC Midgett because of dangerous weatherdeck conditions (Ryerson and Longo 1992). However, dipping bucket samples indicate that average salinities differed by only about $1 \%$ between the two icing events. Though Shellard's (1974) review found the importance of sea water salinity to be small in influencing icing rate, others have found it to be important in assessing the mass and thermodynamics of icing (Brown and Roebber 1985). Jorgensen (1982) reports icing to begin at higher temperatures when salinities are lower. Makkonen (1987) and Gates et al. (1986) make a strong case about the effect of salinity on the "sponginess" of ice, its thermodynamics, and its mass. The salinities and their variation observed aboard the cutter fell well within values observed in other ship icing studies (Shellard 1974).

\section{Accreted ice thickness}

Superstructure ice never accreted to more than 4.4 $\mathrm{cm}$ thickness aboard the cutter (Table 2). Samples of ice were taken at the end of the February icing event, but no samples were taken during it (Fig. 7). Thicknesses of samples ranged from $1.6 \mathrm{~cm}$ on the forward bulkhead to $3.2 \mathrm{~cm}$ at location F1 on the deck forward of the 5-in. gun (Fig. 8, Table 2). During the March icing event, samples were taken at three different times during the event (Fig. 7). Up to $4.4 \mathrm{~cm}$ of ice formed on the main deck during the March event, and $3.4 \mathrm{~cm}$ of ice formed on the port vertical surfaces of the 5-in. gun housing. As in the February event, ice thicknesses, overall, were small, and most ice formed on the port side because, in both events, seas approached principally from port.

The mean thickness of ice on horizontal surfaces at the end of the February icing event was $2.6 \mathrm{~cm}$, and the average thickness on vertical surfaces was $2.2 \mathrm{~cm}$. During the March icing event, horizontal surfaces averaged $2.0 \mathrm{~cm}$ of ice, and vertical surfaces averaged $1.5 \mathrm{~cm}$, indicating that ice on vertical surfaces was about $75 \%$ of the thickness of ice on horizontal surfaces (Ryerson 1995).

Automated time-series measurements of ice thickness on the ship, though not highly accurate in absolute terms, did provide trends in ice thickness through icing events (Ryerson 1995). These trends suggest that there are accretion and ablation sub-events within the primary ice-accretion event. These sub-event patterns, 
greater than on vertical surfaces in the February icing event, but there was no significant difference in March.

Kultashev et al. (1972) found the density of ice on Soviet fishing trawlers to vary between 0.71 to 0.967 $\mathrm{Mg} \mathrm{m}^{-3}$. Tabata et al. (1963) found densities on four ships, totaling 121 samples, to vary between 0.62 and $0.94 \mathrm{Mg} \mathrm{m}^{-3}$, though there was no systematic change of density with location.

\section{Salinity}

The salinities of melted samples were measured with a temperature compensating Beckman Solubridge. All salinities were corrected to a reference temperature of $25^{\circ} \mathrm{C}$. Measurement precision is estimated at $\pm 0.2 \%$.

Mean ice bulk salinity on horizontal surfaces was about $8-10 \%$ larger than on vertical surfaces in both icing events (Table 2). Ice samples were taken on the ship whenever there was an opportunity, thus the length of time that brine had drained since the last splashing by sea water is unknown. However, during several sampling excursions in the March spray event, spray was lofted over the ice sampling team as ice was being removed. In most cases, the ice was no more than a few hours old since the last ice accretion had occurred. Panov (1972) found generally higher ice salinities from similar sea water salinities on a Soviet trawler than were measured on the USCGC Midgett. On both horizontal and vertical surfaces, 10 to 12 hours into an icing event, Panov's salinities ranged from 10.3 to $37.5 \%$.

\section{Porosity}

A significant portion of spray-accreted saline ice often is composed of unfrozen water trapped within the ice matrix (Gates et al. 1986, Makkonen 1987). It is called "spongy" ice; wind tunnel experiments have demonstrated that unfrozen water contents can total up to $50 \%$ of the mass of the deposit.* If the unfrozen brine eventually drains, as happens quickly during and immediately after accretion and more slowly later, the mass of the accretion will be considerably reduced below what thickness alone may suggest.

Air and brine volumes, collectively termed total porosity, of ice samples removed from decks and bulkheads were computed using equations developed by Cox and Weeks (1983) and Frankenstein and Garner (1967). The volumes computed are estimates, as the equations were developed for floating sea ice, not spray ice, and the answers rely upon density, salinity, and temperature measurements that, with all potential errors considered, could cause uncertainty in the porosity esti-

*Personal communication with Edward Lozowski, University of Alberta, 1999. mates. The derived brine volumes and air contents of the accreted ice are calculated for the in-situ temperatures measured at the time of sampling (Table 2, Fig. 9).

Total porosity and its constituent air and brine volumes varied considerably between ice on vertical and horizontal surfaces, and between the February and March icing events. In the February event, total porosities were generally larger on vertical surfaces (Table 2). Ice on all surfaces was cold in the February event, and samples were taken hours after spraying had ceased. With one exception, total ice porosity in the March event was much greater on horizontal surfaces than on vertical surfaces (Table 2). During sampling, most ice in the March event was very wet because of continual splashing and warm weather, which may have contributed to the generally higher porosity on the decks.

A larger proportion of pores is filled with brine on horizontal surfaces than on vertical surfaces in both events (Table 2). Brine drains more readily from ice pores on vertical surfaces, which then fill with air. A larger proportion of March ice pores are filled with brine than are February pores. This may be the result of the higher temperatures in the March event (Fig. 10).

\section{MICROSTRUCTURAL STUDIES OF ACCRETED ICE}

Few studies have examined the crystalline structure of ice created from bow spray. Ono (1968) sectioned ice removed from handrails of the patrol boat Chitose and photographed crystals through crossed polarizers. He found tiny crystals, about $0.5 \mathrm{~mm}$ in diameter, with random orientations. The only other study, conducted by Golubev (1972), was quite thorough, and examined the relationship between crystal structure and orientation of the icing surface, substrate material, distance within the ice from the substrate, and air temperature. Golubev's work was done on a medium size Soviet fishing trawler in the Sea of Japan.

In this work, several ice structure characteristics were examined, including ice crystal shape, size, and orientation, and inclusion size and shape. The February icing event is the least difficult to analyze because temperatures were low during the entire period. The warm weather late in the March event complicates understanding of ice characteristics during that second event (Fig. 7).

Samples were prepared for microstructural analysis by freezing portions of the superstructure ice onto glass slides and then reducing them to the requisite thickness on a microtome. Initially, these sections were thinned to $1-2 \mathrm{~mm}$ thickness and then photographed. 


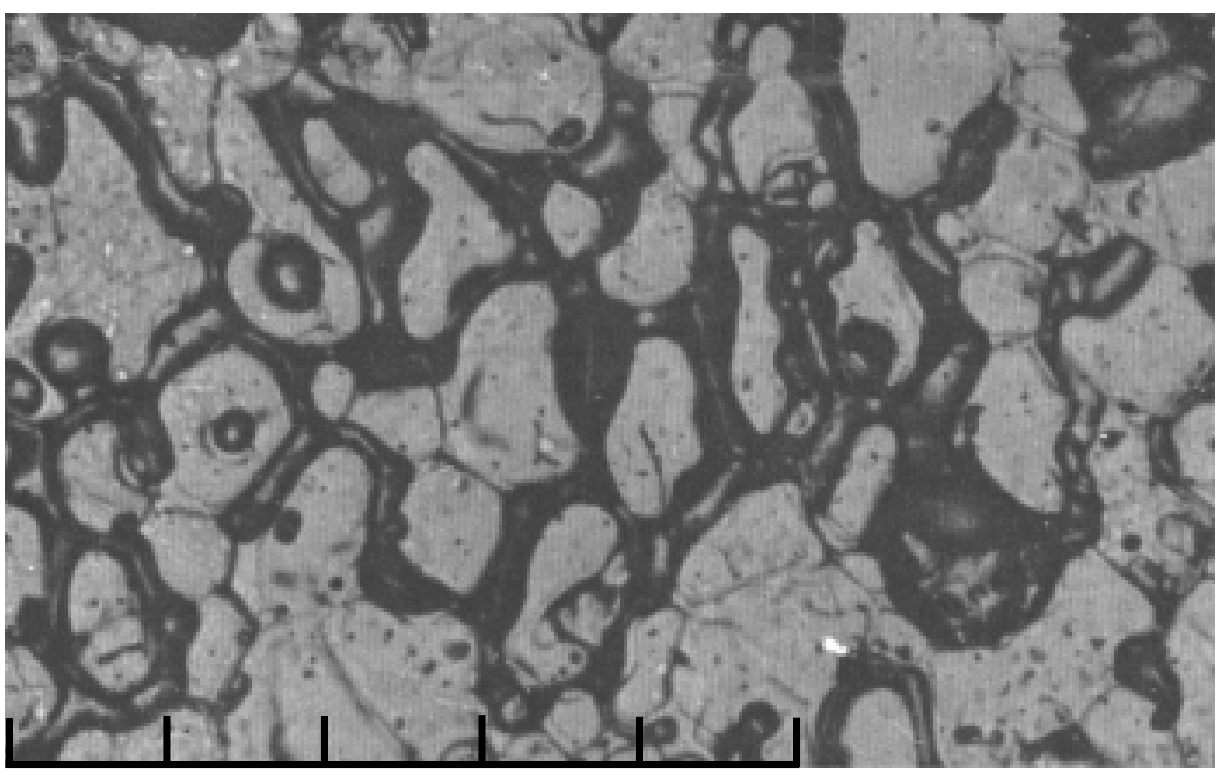

a. Sample M12.

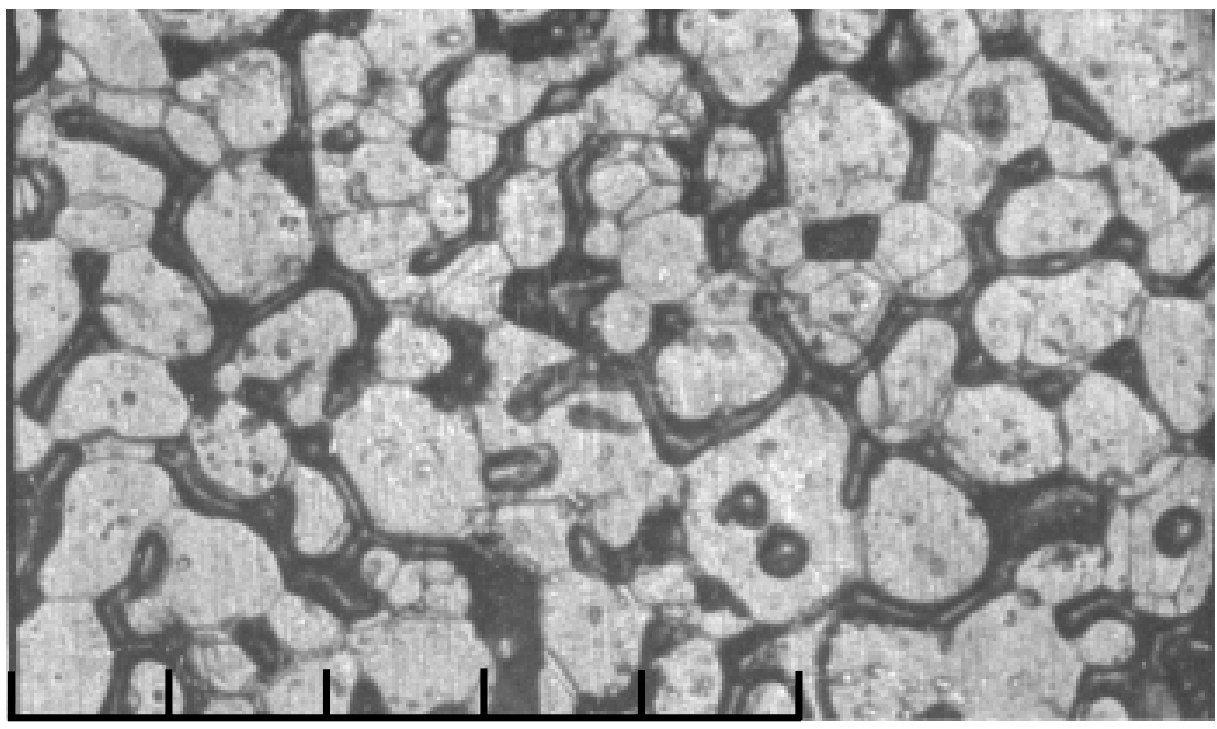

b. Sample M6.

Figure 10. Thin sections of ice sampled during the March icing event from a bulkhead (sample M6) and an icicle (sample M12), illustrating grains encircled by large channelized networks filled with brine (scales in millimeters).

However, to improve the resolution of the microstructure for crystallographic examination, the sections were microtomed further until they measured $0.5 \mathrm{~mm}$ or less in thickness, depending on the average size of crystals in the section. Sections were prepared both parallel and normal to the accretion surface. A Bausch and Lomb extension (bellows) camera fitted with polarizers was used to obtain structure photographs of each thin section. Photographs were taken at $7.5 \times$ magnification on sheet film measuring $17.5 \times 12.5 \mathrm{~cm}$. Contact prints, which constitute a ready source of pictures that can be compared and evaluated at a moment's notice, were used to document textural characteristics of the accreted ice (crystal/inclusion relationships) and to measure crystal and inclusion sizes.

\section{Crystal size measurements}

Determining crystal size in thin sections usually requires measurement of either the diameter or the crosssectional area of grains. Seligman (1949), for example, 
used a method of least-circle diameters to measure grain sizes in rubbings of ice. Alhmann and Droessler (1949) measured the shortest and longest axes of ice grains to obtain average cross-sectional areas. Schytt (1958) and Stephenson (1967) employed much the same technique to measure crystal sizes in Antarctic firn. These methods all suffer from the problem that a section seldom cuts crystals at their maximum (true) diameter, leading to underestimates of the true sizes of crystals. Variations in particle size also complicate the problem, which is further compounded by the lack of knowledge concerning the distribution of particle sizes within the original sample. Because under-sized cuts of crystals in a thin section exert a disproportionate influence on the average particle size, we decided to restrict measurements of crystal size in accreted ice to the 50 largest crystals in a given area of the section (Gow 1987).

As applied to the samples of accreted ice obtained on the cruise of the USCGC Midgett, an area of $10 \times 8$ $\mathrm{cm}$ on the enlarged print $(17.5 \times 12.5 \mathrm{~cm})$ was used to select the 50 largest crystals. This selection of crystals generally constituted less than $25 \%$ of the total number of crystals in the $10-\times 8-\mathrm{cm}$ area of the contact print. Actual values of the cross-sectional areas of crystals were calculated from measurements of length and breadth made with a pocket comparator, which, allowing for the $7.5 \times$ magnification of the contact print, permitted measurements to the nearest $0.05 \mathrm{~mm}$. The mean cross-sectional areas of crystals $\left(\mathrm{mm}^{2}\right)$ were then converted to root-mean-square diameters $(\mathrm{mm})$. This measurement method was preferred to the intercept method because of the substantial corrections needed to account for intersected inclusions, both air bubbles and brine channels, which occur abundantly in accreted ice. With the exception of one or two thin sections, crystal size measurements reported here were restricted to sections cut parallel to the accreting surface.

\section{Inclusion size measurements}

We also attempted to measure air bubble dimensions in the majority of the thin sections, despite the intrinsic difficulty of distinguishing air bubbles from brine pockets trapped in the ice. Although this distinction between these two principal types of inclusions trapped in the ice is difficult to establish with certainty, those we identified as air bubbles tended to be found either along grain boundaries or at multigrain intersections. We concentrated our measurements of bubble size on spherical inclusions, which we believe are more likely to represent air bubbles than brine pockets. Small rounded

\begin{tabular}{|c|c|c|c|c|c|}
\hline Sample & Accretion surface & $\begin{array}{c}\text { Thin } \\
\text { section } \\
\text { orientation }\end{array}$ & $\begin{array}{l}\text { Mean crystal } \\
\text { area }\left(m^{2}\right)\end{array}$ & $\begin{array}{c}\text { Root mean } \\
\text { square } \\
\text { diameter }(\mathrm{mm})\end{array}$ & $\begin{array}{c}\text { Mean bubble } \\
\text { diameter }(\mathrm{mm})\end{array}$ \\
\hline F1 & Deck & Horizontal & 0.63 & 0.79 & 0.26 \\
\hline $\mathrm{F} 2$ & Deck & Horizontal & 0.45 & 0.67 & 0.28 \\
\hline F3 & Superstructure vertical surface & Vertical & 0.60 & 0.78 & 0.20 \\
\hline F4 & Superstructure vertical surface & Vertical & 0.38 & 0.62 & Not measured \\
\hline F5 & Superstructure vertical surface & Vertical & 0.40 & 0.63 & 0.23 \\
\hline F6 & Deck hatch & Horizontal & 0.59 & 0.77 & 0.25 \\
\hline F7 & 5-in. gun forward face & Vertical & 0.62 & 0.79 & 0.26 \\
\hline F8 & 5-in. gun forward face & Vertical & 0.46 & 0.68 & 0.25 \\
\hline F9 & Superstructure vertical surface & Vertical & 0.66 & 0.81 & 0.29 \\
\hline M3 & Superstructure vertical surface & Vertical & 0.58 & 0.76 & 0.27 \\
\hline M5 & 5-in. gun forward face & Vertical & 0.31 & 0.56 & 0.27 \\
\hline M6 & 5-in. gun forward face & Vertical & 0.53 & 0.72 & Not measured \\
\hline M8 & Deck near 5-in. gun & Horizontal & 1.33 & 1.15 & 0.29 \\
\hline M9 & 5-in. gun vertical face Port side & Vertical & 0.50 & 0.71 & 0.31 \\
\hline M10 & 5-in. gun vertical face Port side & Vertical & 0.58 & 0.76 & 0.24 \\
\hline M12 & Icicles, 5-in. gun mount & Horizontal & 0.73 & 0.85 & 0.27 \\
\hline \multirow[t]{2}{*}{ M12 } & Icicles, 5-in. gun mount & Vertical & $2.66^{*}$ & $1.63^{*}$ & Not measured \\
\hline & & & $0.83 \dagger$ & $0.91 \dagger$ & \\
\hline \multirow[t]{2}{*}{ M13 } & Deck near 5-in. gun & Horizontal & $3.53^{*}$ & $1.88^{*}$ & 0.25 \\
\hline & & & $1.06 \dagger$ & $1.03+$ & \\
\hline M14 & 5-in. gun forward face & Vertical & 1.05 & 1.02 & 0.24 \\
\hline
\end{tabular}


inclusions were frequently observed within crystals. This might be interpreted as evidence of incidental grain growth (recrystallization) that most likely occurred in the accreted ice some time after its formation but prior to sampling or sectioning.

\section{Crystal orientation observations}

We made no attempt to determine preferred crystal orientation using universal stage techniques. However, after examining the general nature of interference color changes in the crystal aggregates when a section was rotated between crossed polarizers, it appeared to us that c-axis orientations were substantially random. Dimensional orientation of crystals was, however, observed in sections cut from icicles. The results of crys- tal size measurements of 19 of the 23 samples collected during the cruise are presented in Table 3; also, bubble sizes were obtained for 16 of the 19 samples sectioned for microstructural analysis.

Descriptions of the microstructural characteristics of a selection of samples of accreted ice follow.

\section{RESULTS AND DISCUSSION}

\section{February icing event \\ Vertical surfaces}

Sample F3. This is a bulkhead sample collected $0.5 \mathrm{~m}$ above the deck and from the same general location as samples F4 and F5. Sample F3 (Fig. 11)

Figure 11. Sample F3, taken from the face of the forward bulkhead and about $0.5 \mathrm{~m}$ above the deck surface (scales in millimeters).

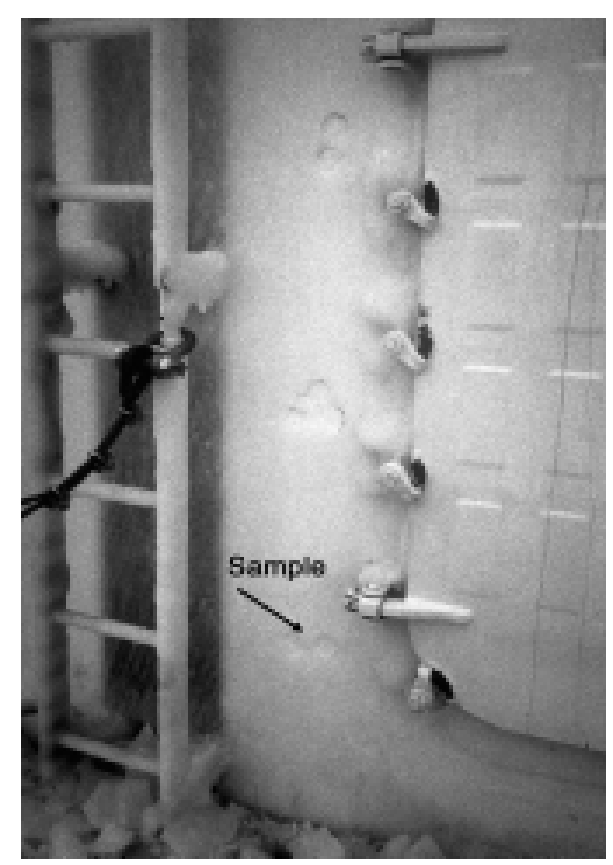

a. Sample location.

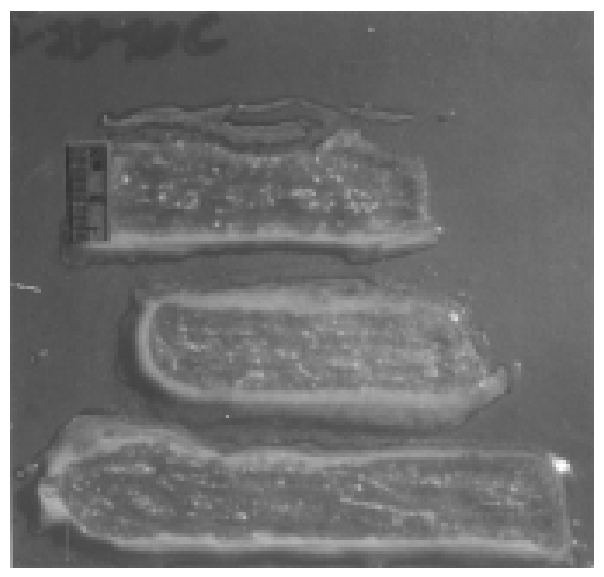

b. Thick sections photographed in natural light.

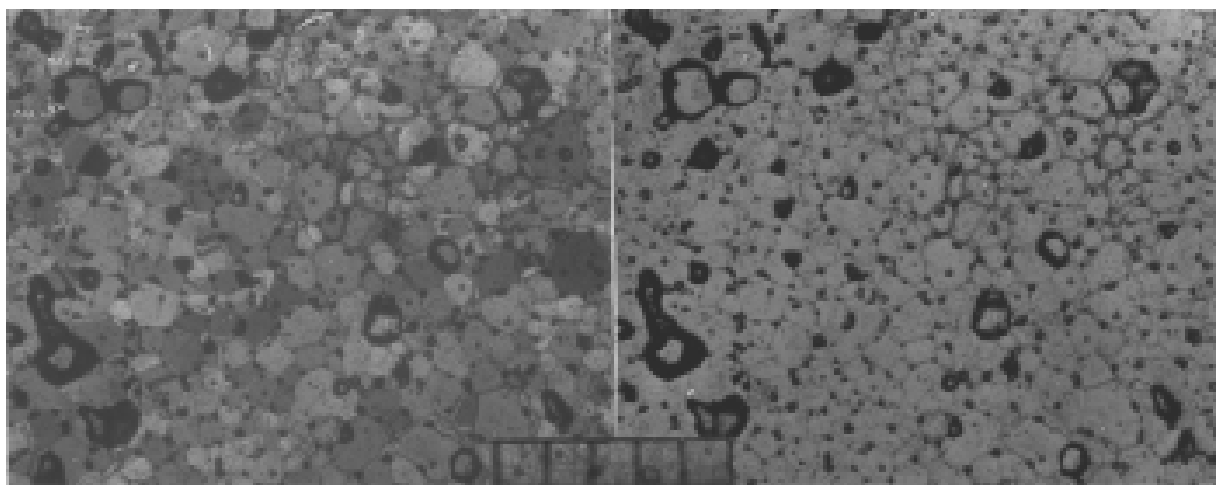

c. Thin sections photographed in natural light (right) and between crossed polarizers (left). 


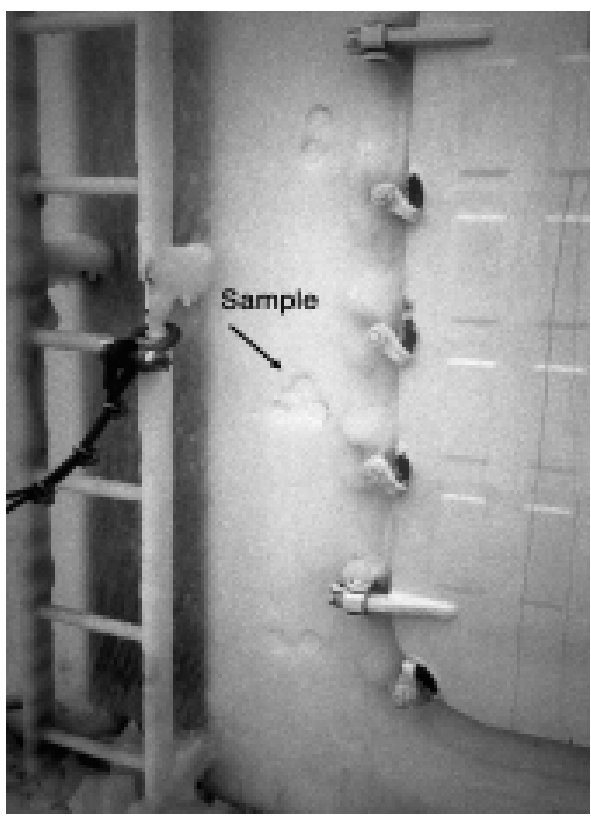

a. Sample location.

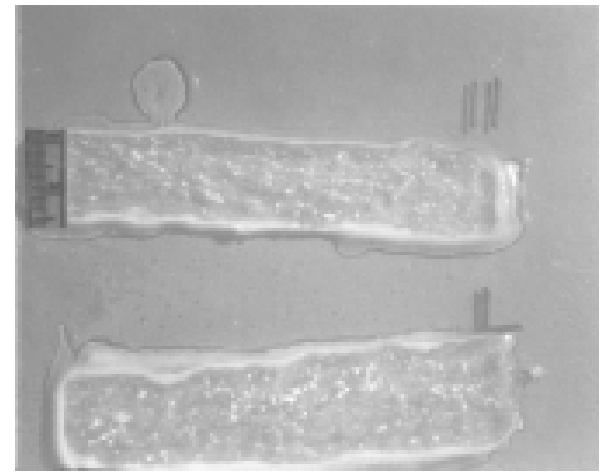

b. Thick sections photographed in natural light.

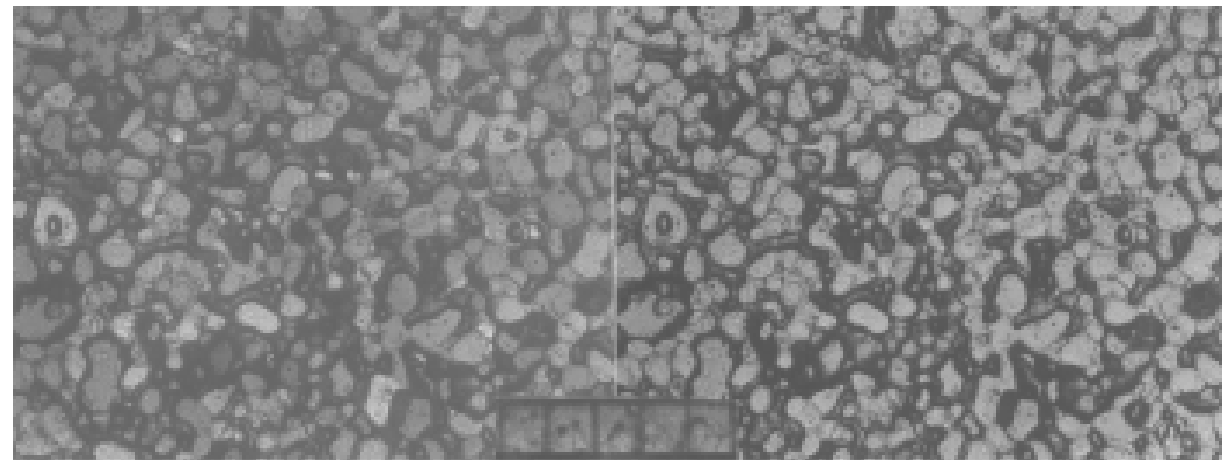

c. Horizontal thin sections photographed in natural light (right) and between crossed polarizers (left). Note rounded shape of ice crystals.

Figure 12. Sample F4, taken from the forward bulkhead on the main deck (scales in millimeters).

exhibits very weak layering in the vertical section, as was also observed in sample F4 (Fig. 12). Density, salinity, and brine inclusion characteristics were very similar to those measured in sample F4. A mean bubble diameter was also measured. However, crystals in sample F3 are much larger than in sample F4, averaging $0.60 \mathrm{~mm}^{2}$ in cross-sectional area compared to 0.38 $\mathrm{mm}^{2}$ in sample F4, even though sample F3 was obtained from a lower level on the bulkhead than sample F4. The reason for this difference in crystal size is not known. This result serves to demonstrate that there can be significant differences in crystalline texture over short distances of superstructure icing.

Sample F4. This is a bulkhead sample, $1.6 \mathrm{~cm}$ thick, that was retrieved $1 \mathrm{~m}$ above the deck (Fig. 12). The vertical thick section shows little evidence of layering. Grains in horizontal thin sections can be seen to possess generally rounded outlines. Multi-crystalline grains occur abundantly in sample F4 and the mean crystal cross section, $0.38 \mathrm{~mm}^{2}$, was the smallest measured in the February icing series. Salinity was $14.1 \%$. Derived 


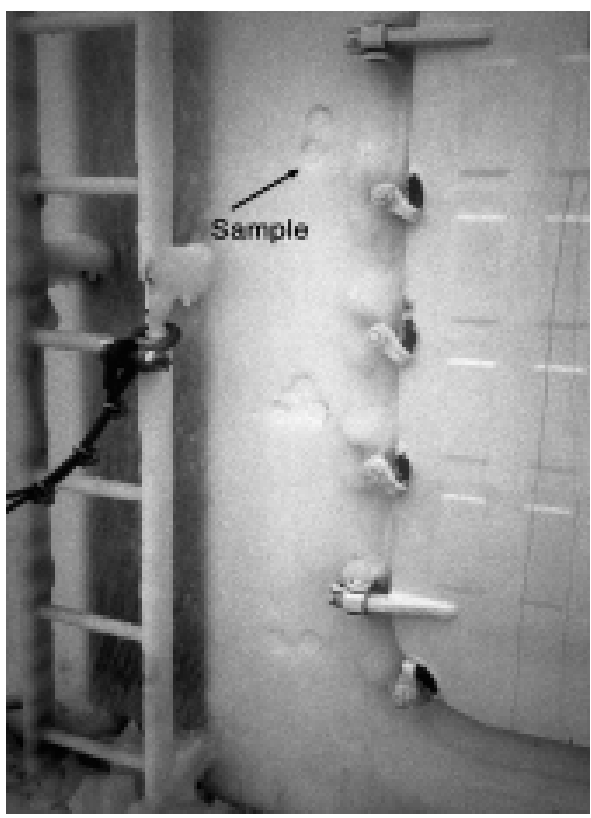

a. Sample location.

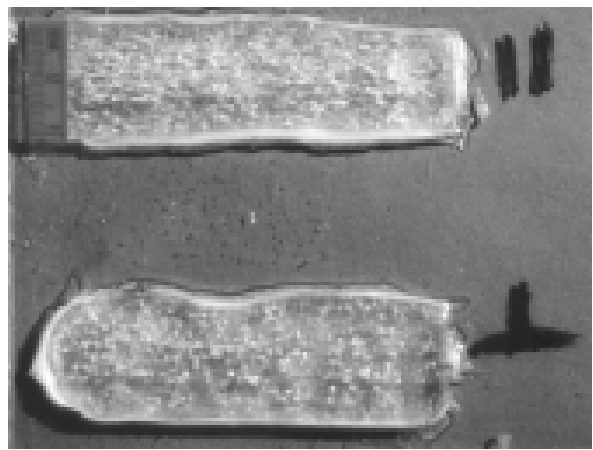

b. Thick sections photographed in natural light.

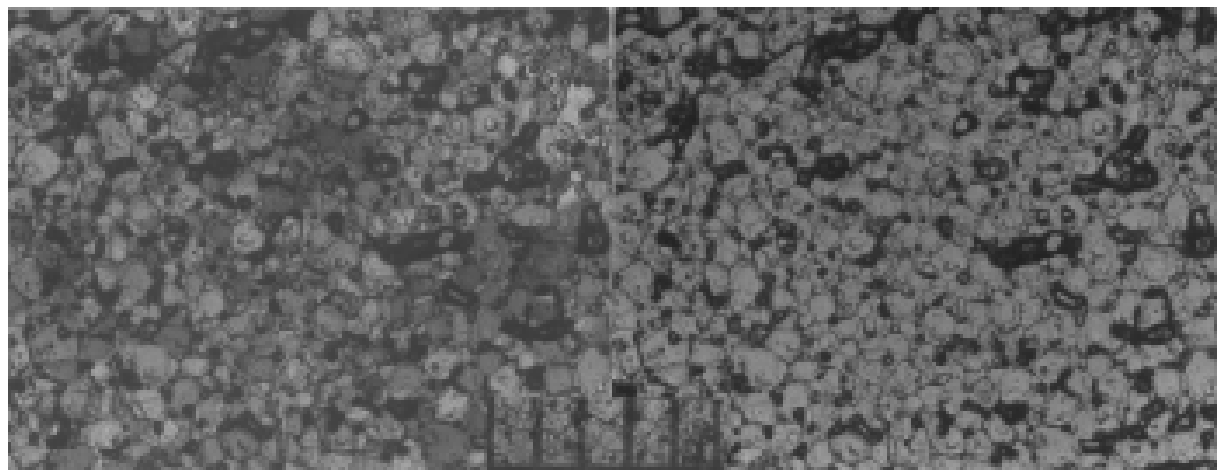

c. Thin sections photographed in natural light (right) and between crossed polarizers (left).

Figure 13. Sample F5, taken about $1.5 \mathrm{~m}$ above the deck surface on the face of the forward bulkhead (scales in millimeters).

values of brine and entrapped air volume calculated at the in-situ temperature of $-7.8^{\circ} \mathrm{C}$ are 7.9 and $18.6 \%$, respectively.

Sample F5. This is a bulkhead sample (Fig. 13) obtained $1.5 \mathrm{~m}$ above the deck and from the same general location as samples F3 and F4. Crystal size was very similar to that of sample F4. However, as indicated in Tables 2 and 3, other physical properties of sample F5 differ appreciably from those measured on samples F3 and F4. Sample F5 is less saline, but sig- nificantly denser, leading also to appreciable differences in the derived values of the entrapped air and brine volumes. Those differences indicate either less brine was incorporated initially or that the region from which sample 5 was collected underwent somewhat greater brine drainage after deposition than nearby samples F3 and F4, perhaps because of the greater height of sample F5 above the deck.

Sample F7. This sample was taken from the same general location as sample F8, from the forward face 


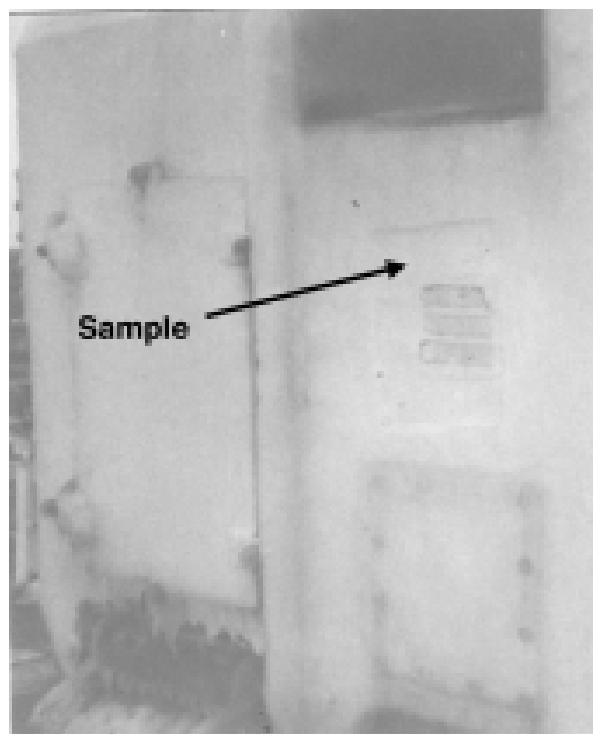

a. Sample location.
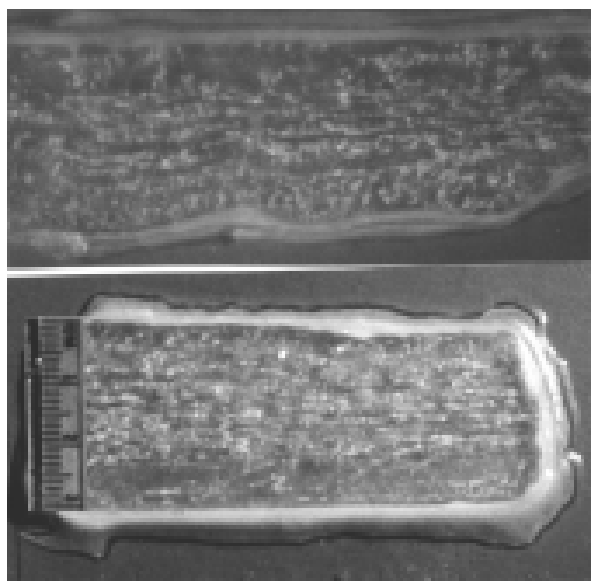

b. Thick sections photographed in natural light.



\section{c. Horizontal thin sections photographed in natural light (right) and between crossed polarizers (left).}

\section{Figure 14. Sample F7, taken from the forward face of the 5-in. gun mount (scales in millimeters).}

of the 5-in. gun mount as indicated in Figure 8, at 1.1 $\mathrm{m}$ above the deck surface (Fig. 14). This particular sample displays clearly defined layer structure, testifying to the episodic nature of ice accretion on the vertical face of the gun mount. Crystal shape varies from subrounded to polygonal, with crystal cross-sectional areas averaging $0.62 \mathrm{~mm}^{2}$. The structure also included regions of localized brine entrapment. A bulk salinity of $16.2 \%$ was measured in conjunction with a measured density of $0.773 \mathrm{Mg} \mathrm{m}^{-3}$. Derived values of brine and entrapped air volume, calculated at the in-situ temperature of $-8.0^{\circ} \mathrm{C}$, of 9 and $17.6 \%$ were obtained.

Sample F8. This sample (Fig. 15) was obtained from the same general location as sample F7 (Fig. 14).
Both exhibit strong layer structure in thick sections. However, the two samples differ appreciably in their overall physical properties, as indicated in Tables 2 and 3. Sample F8, obtained $0.2 \mathrm{~m}$ below sample F7, is both less dense and less saline than sample F7, resulting in correspondingly significant differences in the derived values of brine and entrapped air volumes. Crystal textures are similar in both samples, but crystal sizes are appreciably smaller in sample F8. These results further indicate the variability in properties that can exist in neighboring samples of the same icing event.

Sample F9. This sample measured $1.9 \mathrm{~cm}$ thick and was obtained from the vertical panel installed by personnel from the U.S. Navy David Taylor Model 


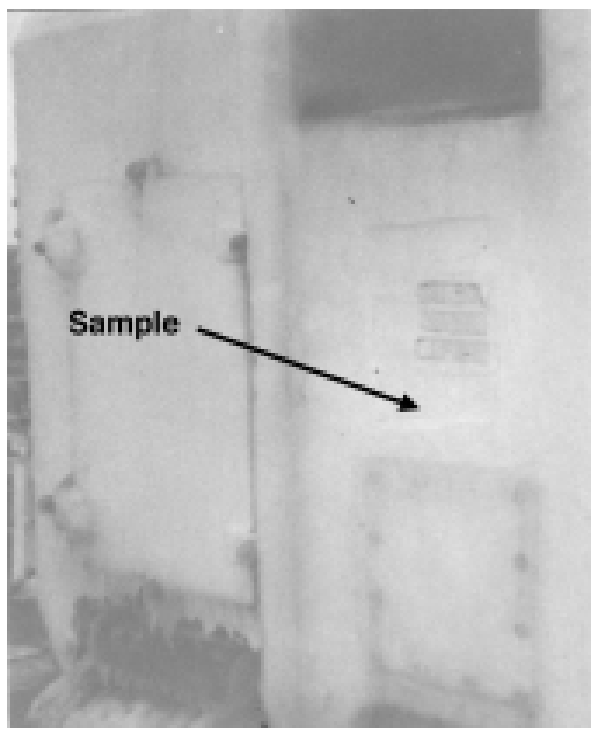

a. Sample location.

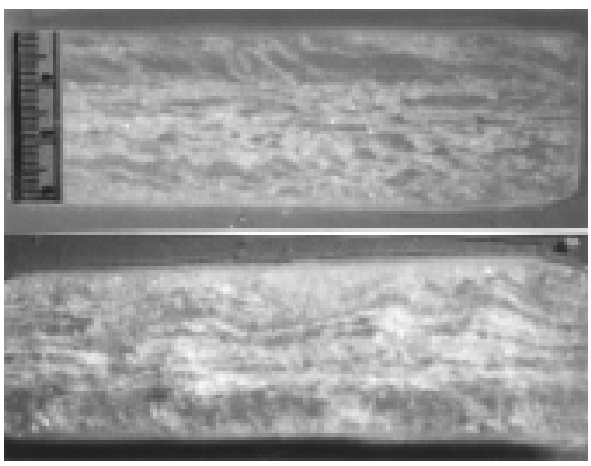

b. Thick sections photographed in natural light.

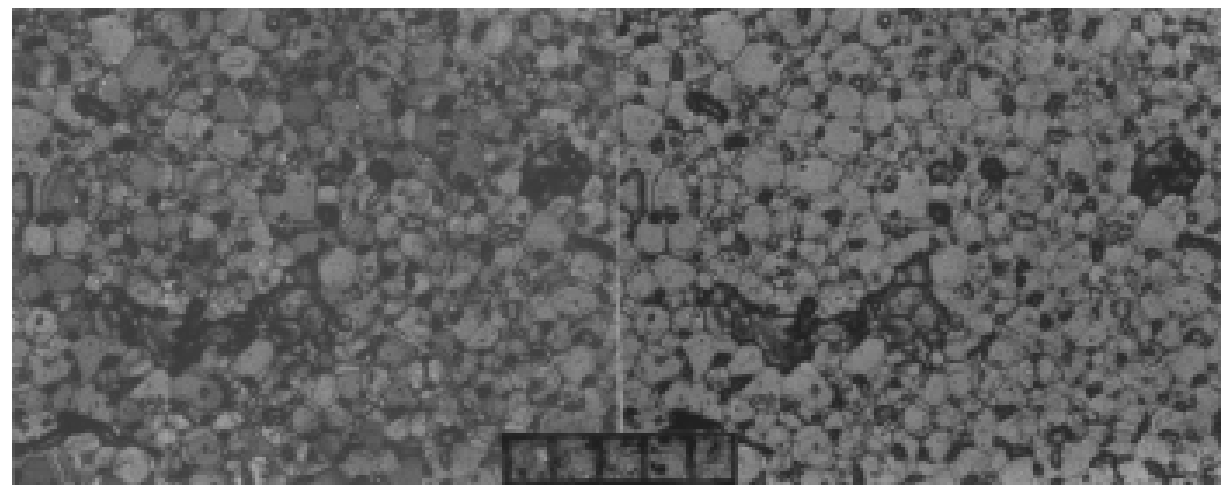

c. Thin sections photographed in natural light (right) and between crossed polarizers (left).

Figure 15. Sample F8, taken $0.9 \mathrm{~m}$ above the deck ( $0.2 \mathrm{~m}$ below sample F7) on the forward face of the 5 -in. gun mount under the barrel (scales in millimeters). Layering is very strongly developed in this sample.

Basin (DTMB) on the starboard forward bulkhead (Fig. 16). Compared to other samples collected during this icing event, the F9 sample was both the least dense $\left(0.693 \mathrm{Mg} \mathrm{m}^{-3}\right)$ and the least saline (11.5\%). Combined with an estimated in-situ measurement temperature of $-8^{\circ} \mathrm{C}$, the density-salinity characteristics of the ice yielded a derived value of $25.7 \%$ for the entrapped air volume, but only $5.7 \%$ for the volume of brine trapped in the ice. The mean size of bubbles in the ice $(0.29 \mathrm{~mm})$ was also the largest measured on any sample from the February icing event. The crystal size was also the largest measured, as indicated in Table 3. An additional feature of the microstructure of this sample of accreted ice is the widespread occurrence of polygonal crystals. These grew in lieu of rounded or even shapeless grains that could be expected of water droplets when they strike the deck or superstructure of a ship and freeze. Most of the grain boundaries show minimal curvature, and $120^{\circ}$ multigrain intersections are dominant. It cannot be determined just when this apparent conversion to polygonal grains took place, but the fact that it has happened emphasizes the importance of thin sectioning samples as soon as possible after the initial accretion, or even during the accretion process, to capture the true condition of the crystal structure. As also applies to previously discussed samples (F1, F3, F4, 


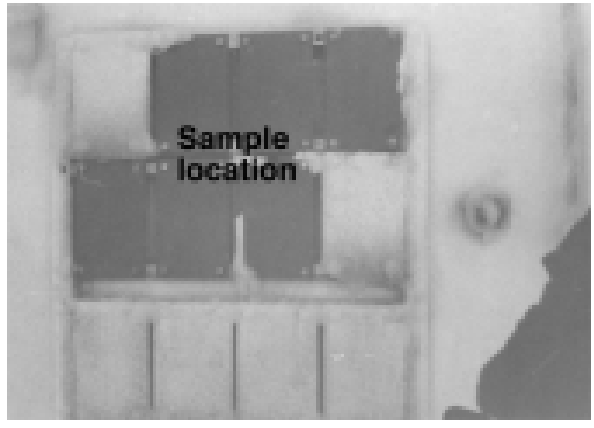

a. Sample location.

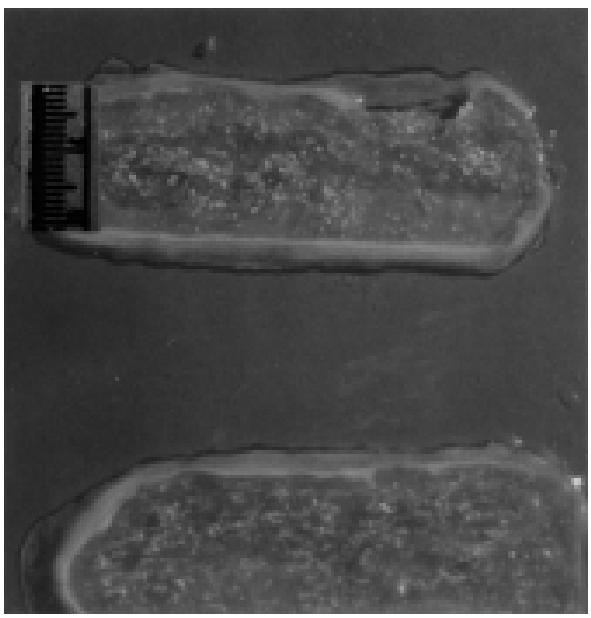

b. Thick sections photographed in natural light.

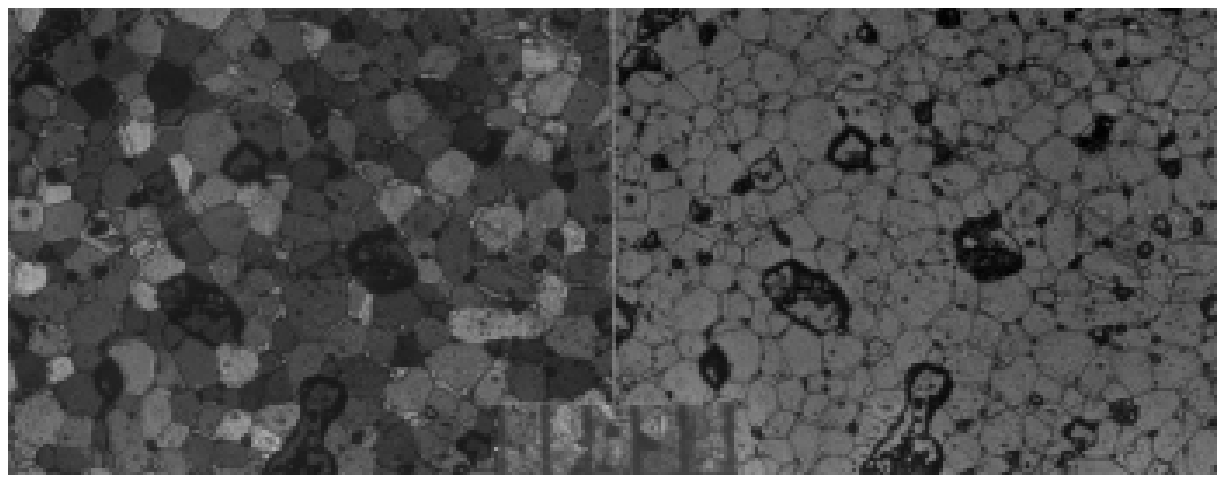

c. Thin sections photographed in natural light (right) and between crossed polarizers (left).

Figure 16. Sample F9, taken from the DTMB ice panel on the starboard forward bulkhead (scales in millimeters). The test panels stand off from the bulkhead surface, allowing cold air to circulate behind them. This allowed ice on the panels to be colder than ice on the adjacent bulkhead.

and F6), no preferred orientation of crystals was apparent, based on observations of the pattern of interference colors displayed when crystals are rotated between crossed polarizers.

\section{Horizontal surfaces}

Sample F1. This is a deck sample, as indicated in Figure 8 , having 3.2-cm-thick ice with a mean density $0.895 \mathrm{Mg} \mathrm{m}^{-3}$ and characterized by a high salinity of $24.0 \%$ (Fig. 17). The salinity data, in conjunction with the in-situ temperature of the accreted ice and its density, yielded a total porosity of $19.2 \%$, consisting of $13.7 \%$ of brine by volume and an entrapped air content of $5.5 \%$. Vertical thick section slices in Figure 17 clearly demonstrate the layered nature of the ice. This may be associated with the episodic spraying and drying process of sea spray accretion, or with the sloshing of water trapped on the deck by frozen scuppers. The mean cross-sectional area of crystals measured $0.63 \mathrm{~mm}^{2}$, equivalent to a root-mean-square diameter of $0.79 \mathrm{~mm}$. Crystals are generally subrounded, though some straightening of the grain boundaries is also apparent. A variety of inclusion structures is present, either concentrated along grain boundaries or located at multigrain intersections. Larger, often irregularly shaped inclusions are identified as brine pockets; smaller, generally rounded inclusions are tentatively identified as air bubbles. Bubbles average $0.26 \mathrm{~mm}$ in diameter or about one-third that of the crystals. Crystal orientation is random, based on observations of the interference colors 


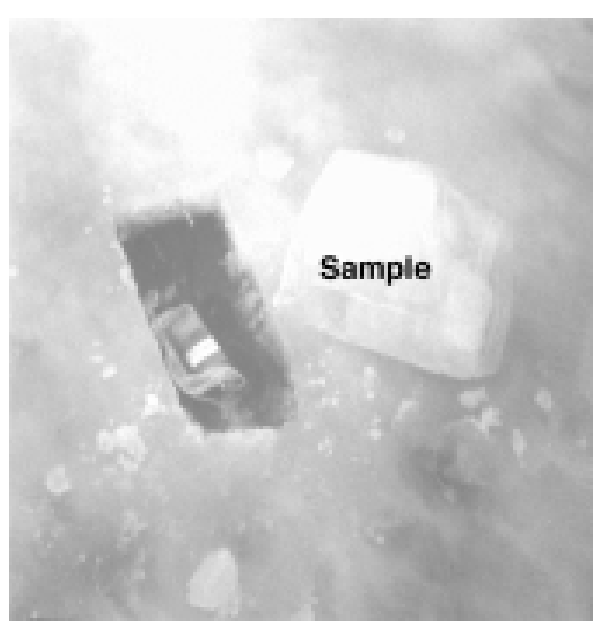

a. Sample location.

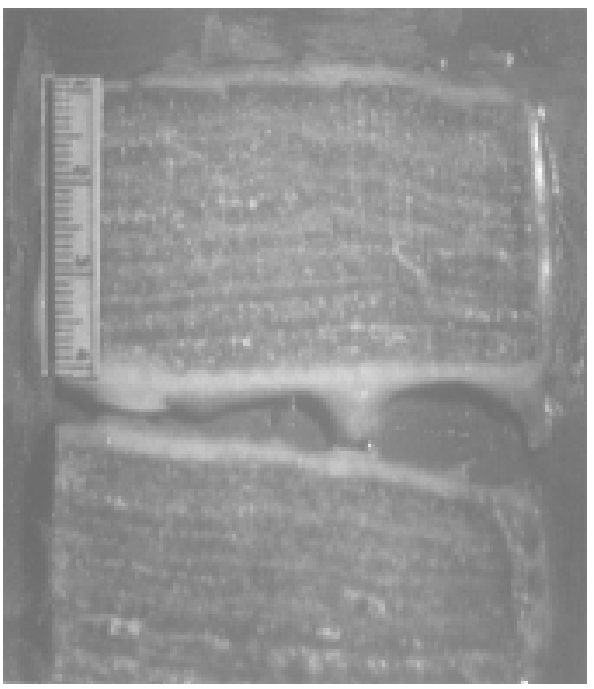

b. Vertical thick sections photographed in natural light.

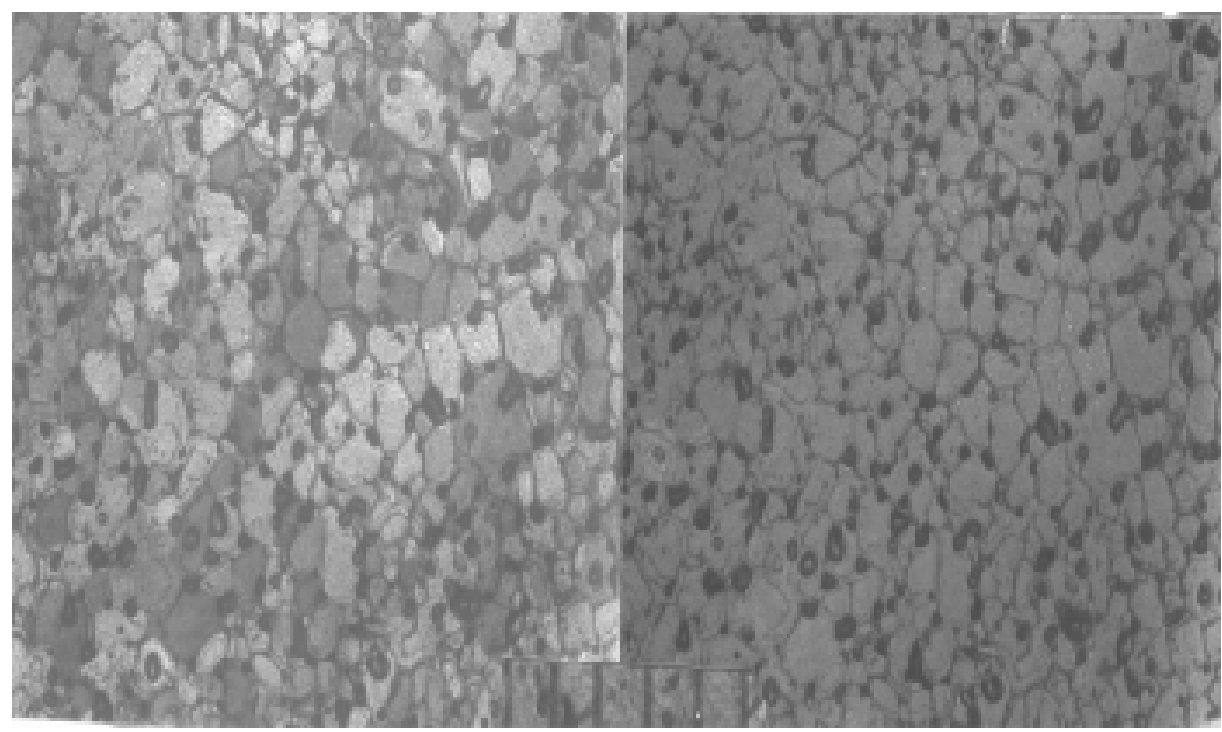

c. Horizontal thin sections photographed in natural light (right) and between crossed polarizers (left).

Figure 17. Sample F1, taken from the main deck during the February icing event (scales in millimeters). Note layering in thick sections. Dark circular inclusions in thin sections are air bubbles.

when the thin section is rotated between crossed polarizers.

Sample F2. This sample (Fig. 18) was obtained from the deck at the location indicated in Figure 8, in proximity to the vertical bulkhead samples F3, F4, and F5. Though it is somewhat thinner $(2.8 \mathrm{~cm})$ than deck sample F1 $(3.2 \mathrm{~cm})$, their physical properties are similar (see Tables 2 and 3), with the exception of mean crystal cross-sectional area, which is somewhat smaller in sample F2 $\left(0.45 \mathrm{~mm}^{2}\right)$ than in F1 $\left(0.60 \mathrm{~mm}^{2}\right)$.

Sample F6. This sample (Fig. 19), measuring 1.8 $\mathrm{cm}$ thick, was obtained from the DTMB ice accretion panel on the top of the hatch on the main deck. DTMB had placed panels on the main deck hatch cover, and on the starboard side of the forward bulkhead, to experiment with ice removal techniques. These panels 


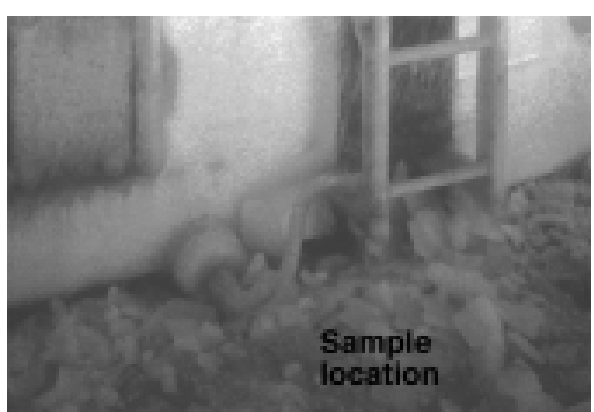

a. Sample location.

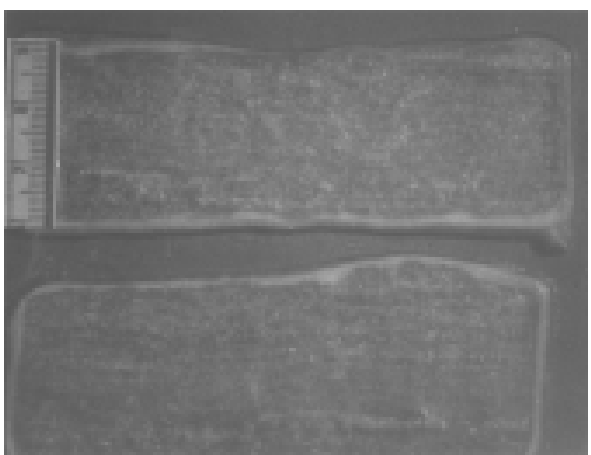

b. Thick sections photographed in natural light.

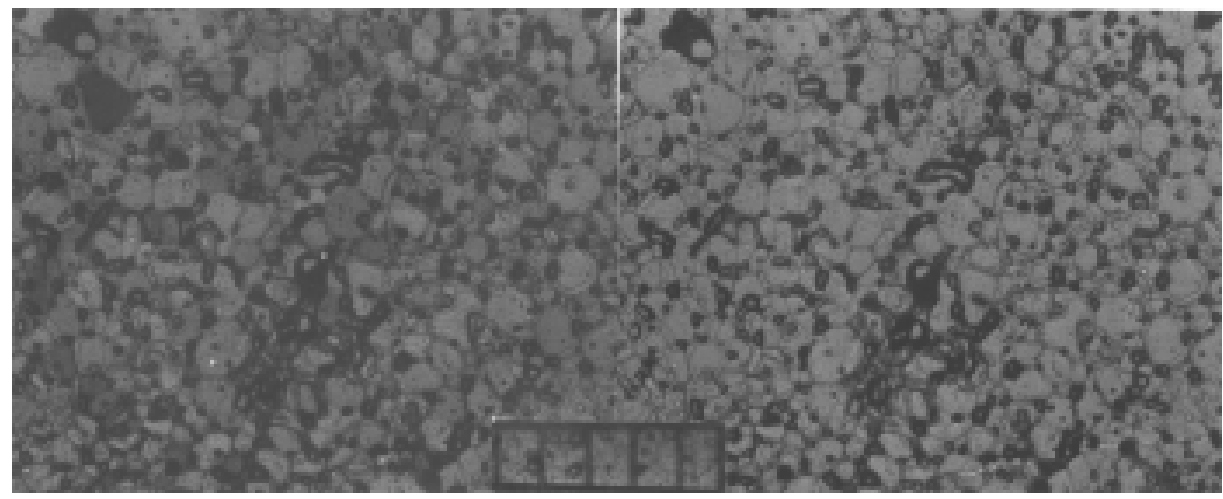

c. Thin sections photographed in natural light (right) and between crossed polarizers (left).

\section{Figure 18. Sample F2, taken from the deck, $25 \mathrm{~cm}$ forward of the bulkhead (scales in millimeters). Physical properties are similar to deck sample F1.}

stood several centimeters off of the hatch cover and bulkhead surfaces, which allowed cold air to circulate behind them, keeping them colder than the hatch cover or bulkhead. The thick section photo displays wavy layering. Though microstructurally similar to the deckaccreted ice at sampling site F1 (Fig. 8 and Fig. 17), many of the crystals are seen to possess straight boundaries that frequently intersect at approximately $120^{\circ}$ angles. This near-equilibrium intersection angle for ice crystals is compatible with some process of recrystallization, possibly at elevated temperatures while the ice was still on the hatch. Such a process has been well documented earlier (Gow 1987). Mean crystal crosssectional area $\left(0.59 \mathrm{~mm}^{2}\right)$ and the derived mean diameter $(0.77 \mathrm{~mm})$ are very similar to values measured on sample F1. Bubble sizes (averaging $0.25 \mathrm{~mm}$ ) are also very comparable to those found for sample F1. Numerous irregularly shaped inclusions are identified as brine pockets. Bulk salinity is essentially the same as mea- sured on sample F1 (24.0\%o). However, the entrapped air volume of $3.3 \%$ (Table 2 ) is appreciably lower owing to the denser nature of the ice accreted on top of the hatch at this site.

\section{March icing event Vertical surfaces}

Sample M3. This sample was retrieved from the vertical front face of the 5-in. gun housing, below the barrel (Fig. 20). The thickness of the accreted ice was $1.1 \mathrm{~cm}$ when sampled. A bulk density of 0.848 $\mathrm{Mg} \mathrm{m}^{-3}$ was measured, which, in conjunction with a measured bulk salinity of $14.8 \%$ and an in-situ ice temperature of $-2.2^{\circ} \mathrm{C}$, gave derived values of brine and entrapped gas volumes of 30.1 and $11.3 \%$, respectively. Microcrystalline characteristics indicate that this sample also suffered modification of its original grain structure since it was accreted. These modifications include substantial straightening of grain boundaries and for- 


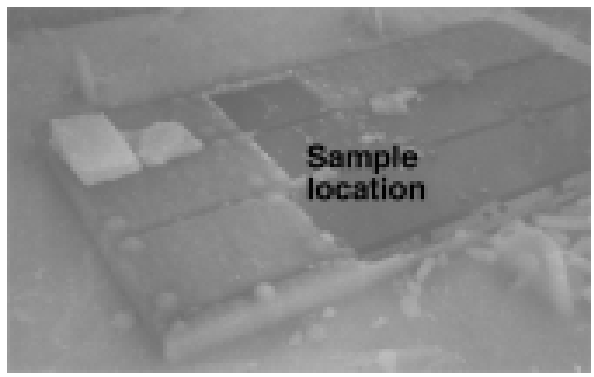

a. Sample location.

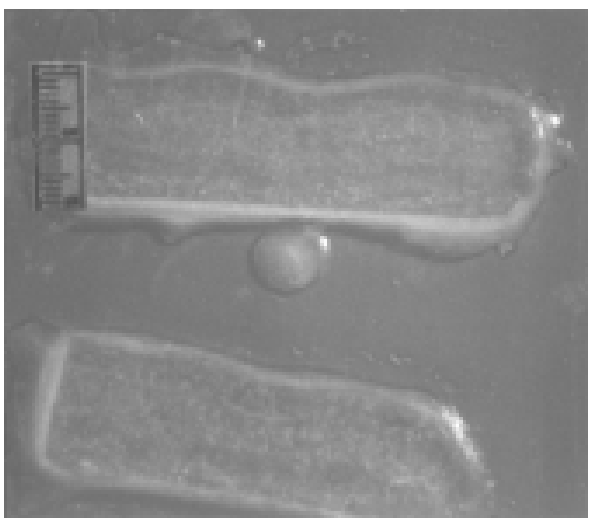

b. Thick section layering photographed in natural light.

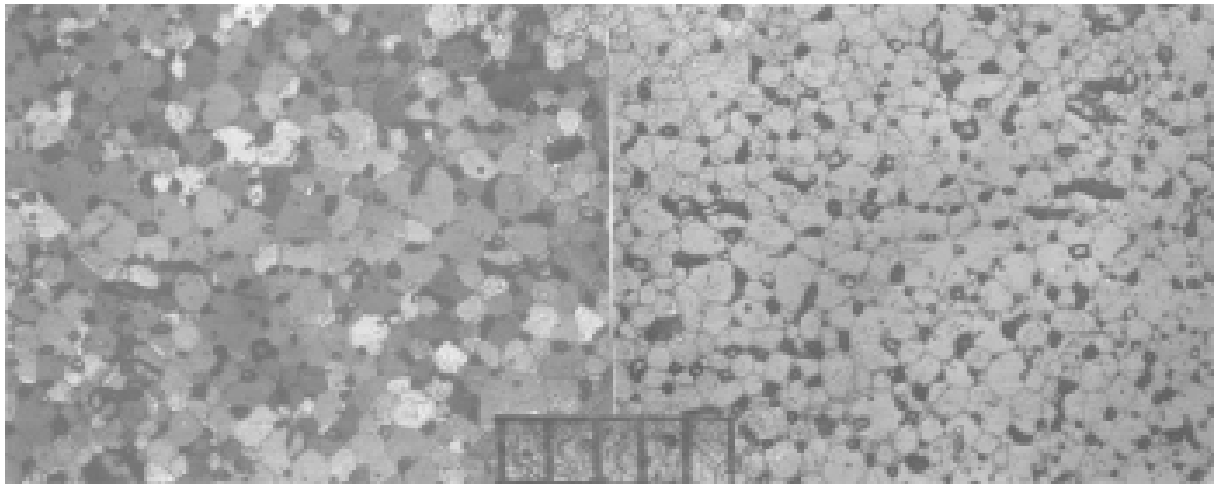

\section{c. Modified ice crystal boundaries photographed in natural light (right) and between crossed polarizers (left).}

Figure 19. Sample F6, taken from the ice accretion panel on the main deck
hatch (scales in millimeters). Dark circles in thin sections are air bubbles. mation of $120^{\circ}$ triple junctions. These changes have not been accompanied by any significant preferred orientation of the component crystals. Crystal cross sections and derived diameters averaged $0.58 \mathrm{~mm}^{2}$ and $0.76 \mathrm{~mm}$, respectively. Bubble diameters averaged 0.27 $\mathrm{mm}$. Large numbers of irregularly shaped structures, including some that encircle crystals, are identified as brine inclusions.

Sample M5. This sample (Fig. 21) was retrieved from the 5-in. gun housing, as was sample M3, but was located at a more elevated level, $0.9 \mathrm{~m}$ above the deck on the front face of the gun housing and about 7.5 hours later than sample M3. This later sampling time is clearly evident in both the ice thickness, only $0.6 \mathrm{~cm}$, and the microstructural characteristics of sample M5. This ice has a granular texture of well-rounded grains, exhibiting the smallest crystal size of any sample of accreted ice collected on the cruise.
The mean crystal cross section measured $0.31 \mathrm{~mm}^{2}$, which converts to a root-mean-square diameter of $0.56 \mathrm{~mm}$. In this particular section, the grains appear substantially immersed in brine, forming channel-like networks similar to what was observed in samples M6 and M12 in Figure 10. The ice also contained many rounded, presumed bubbles of air with a mean diameter of $0.27 \mathrm{~mm}$. A mean density of 0.871 $\mathrm{Mg} \mathrm{m}^{-3}$ was measured in conjunction with a bulk salinity of $10.3 \%$.

Sample M6. This sample (Fig. 22) was obtained from the same general location (vertical port side facing of the 5-in. gun mount) as samples M7, M9, and M10. This sample was only $0.8 \mathrm{~cm}$ thick. A relatively low salinity of $7.9 \%$ was measured, together with a density of $0.799 \mathrm{Mg} \mathrm{m}^{-3}$. Generally, rounded grains characterize the crystalline texture of this sample. Thin section observations give the impression of grains im- 


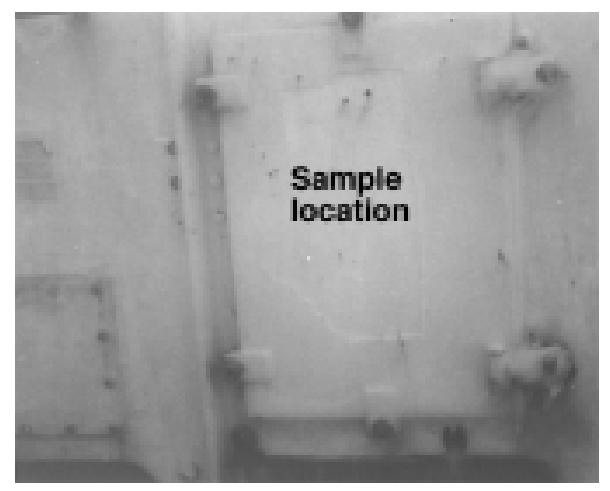

a. Sample location.

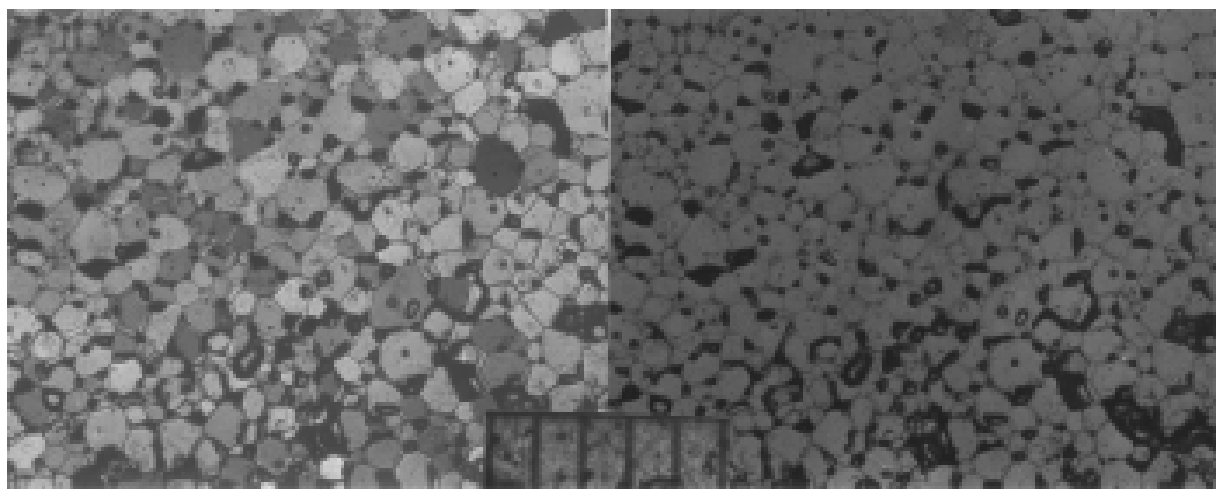

b. Thin sections in photographed natural light (right) and between crossed polarizers (left).

Figure 20. Sample M3, taken from beneath the barrel of the 5-in. gun (scale in millimeters). Thick sections taken in natural light are not available for this sample.



Figure 21. Sample M5, a vertical sample taken from the front of the 5-in. gun housing. No thick section or location photographs are available. Thickness was only $0.6 \mathrm{~cm}$, and it was obtained at nearly the same location as February sample F8. Right to left are thin sections photographed in natural light and between crossed polarizers, respectively (scale in millimeters). 


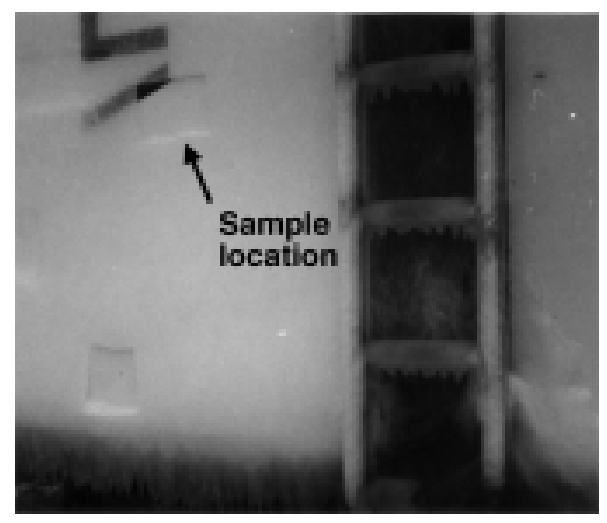

a. Sample location.

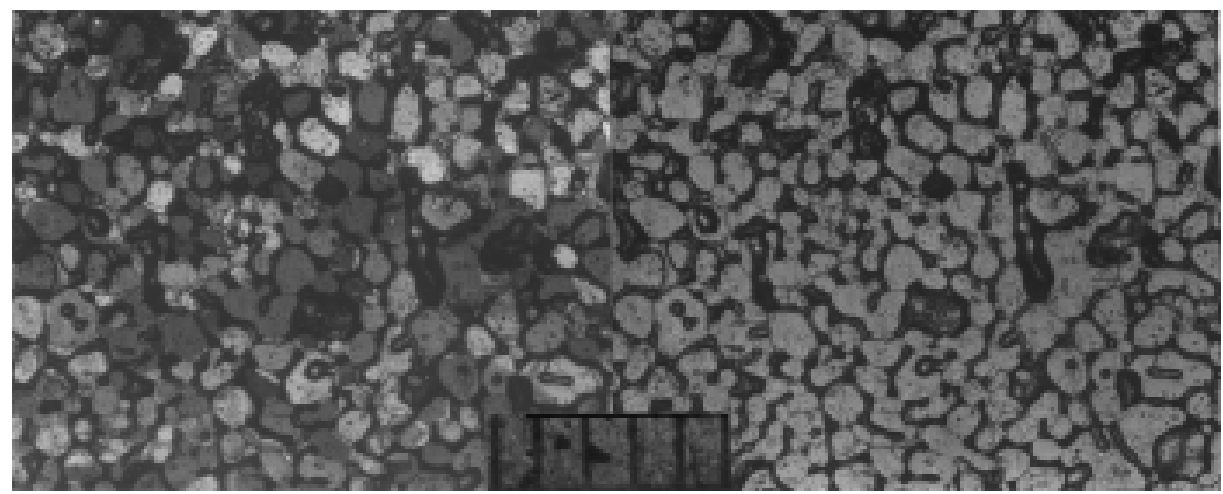

\section{b. Thin sections photographed in natural light (right) and between crossed polarizers (left).}

\section{Figure 22. Sample M6, removed from the port face of the 5-in. gun mount (scale in millimeters). Thick sections photographed in natural light are not available. Air temperature was near $0^{\circ} \mathrm{C}$ when this sample was taken.}

mersed in brine, as indicated in an enlarged section of this sample shown in Figure 10.

Sample M7. This sample, obtained from 1.2-cmthick ice from the same general location as samples M6, M9, and M10, yielded a bulk salinity of $8.6 \%$ and a density of $0.872 \mathrm{Mg} \mathrm{m}^{-3}$. No thin sections of this sample were prepared.

Sample M9. This sample (Fig. 23) was obtained $1.8 \mathrm{~m}$ above the deck from vertically accreted ice, 2.3 $\mathrm{cm}$ thick, from the same general location as sample M6 (Fig. 22), but 16.5 hours later. Structurally, this sample of accreted ice consisted of polygonal crystals of average cross-sectional area of $0.50 \mathrm{~mm}^{2}$, incorporating numerous bubbles and inclusions of brine. The sharply polygonal outlines of the crystals indicate that ice at this particular location may have recrystallized after deposition at the elevated temperatures of this event (see Fig. 7); $120^{\circ}$ multigrain intersections are especially prominent. A density of $0.877 \mathrm{Mg} \mathrm{m}^{-3}$ was measured, which, together with a measured bulk salinity of $7.5 \%$, yields derived values of 6.0 and $11.5 \%$ for the entrapped air and brine volumes, respectively, at the measured in-situ temperature of $-3^{\circ} \mathrm{C}$.

Sample M10. This sample (Fig. 24), measuring 3.4 $\mathrm{cm}$ thick, was taken from a bulkhead located on the port side of the 5 -in. gun at a height of $0.9 \mathrm{~m}$ above the deck. Thick sections cut perpendicular to the accretion surface show evidence of layering. A relatively low bulk salinity of $7.0 \%$ was measured; this, in conjunction with a measured density of $0.882 \mathrm{Mg} \mathrm{m}^{-3}$ at an in-situ temperature of $-3^{\circ} \mathrm{C}$, yields derived values of 10.8 and $5.3 \%$ of brine and entrapped air volume, respectively. The microstructure is composed of a mixture of rounded 


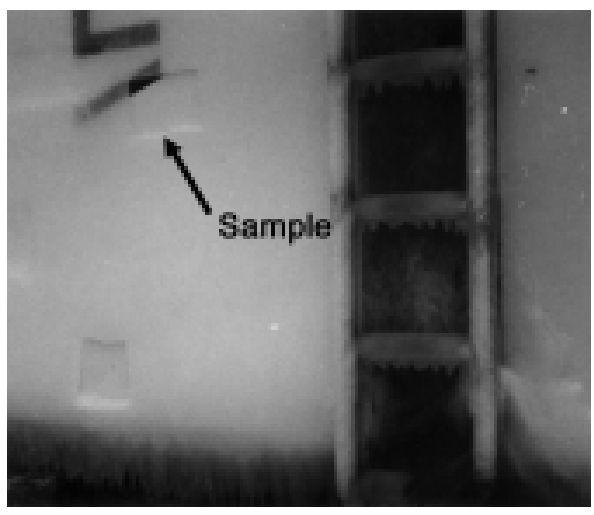

a. Sample location.

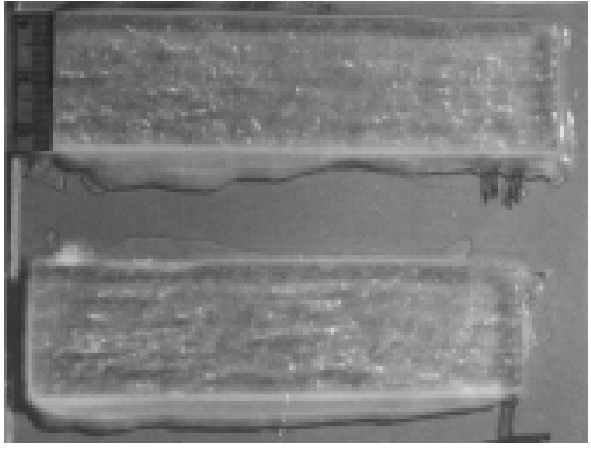

b. Thick sections photographed in natural light.

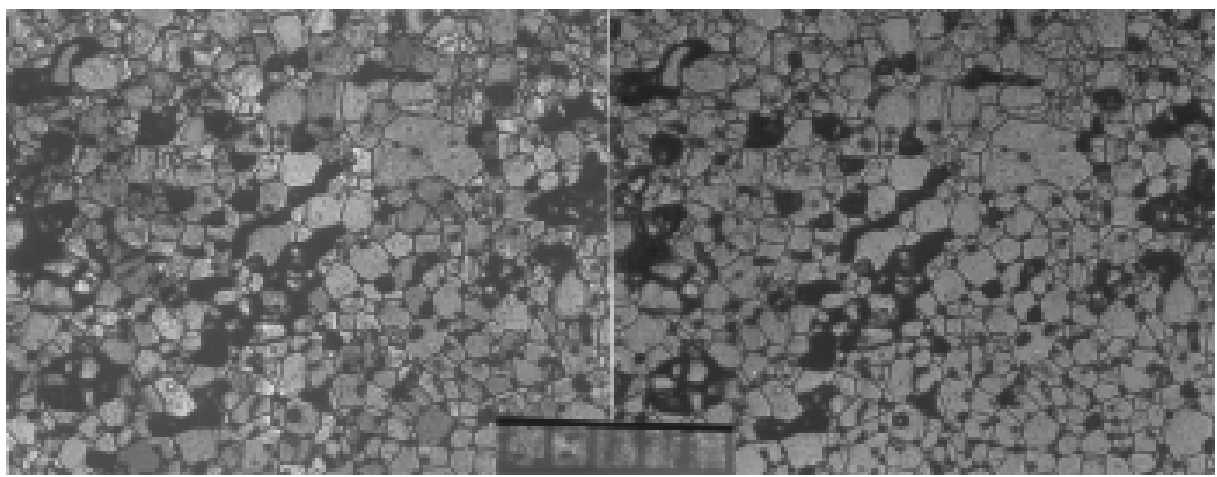

c. Thin sections photographed in natural light (right) and between crossed polarizers (left).

Figure 23. Sample M9, taken from the port bulkhead of the 5-in. gun housing, $1.8 \mathrm{~m}$ above the deck surface (scales in millimeters).

grains and straight-sided crystals, exhibiting occasional $120^{\circ}$ intersections. The latter would indicate partial recrystallization of the ice at some stage of its structure evolution. A mean cross-sectional area of crystals of $0.58 \mathrm{~mm}^{2}$ (and its diameter equivalent of $0.76 \mathrm{~mm}$ ) was measured in conjunction with a mean bubble diameter of $0.24 \mathrm{~mm}$.

Sample M14. Samples of ice were retrieved from this particular location, situated between 1.2 and $1.5 \mathrm{~m}$ above the deck on the front face of the 5-in. gun immediately under the barrel, at three different times during the March icing event. The sample analyzed here (Fig. 25) measured $1.1 \mathrm{~cm}$ thick and was taken at the end of the March event. This sample contained the largest crystals of all the vertically accreted ice samples that we examined; they averaged $1.05 \mathrm{~mm}^{2}$ in cross section, which converts to a root-mean-square diameter of 1.02 $\mathrm{mm}$. Microstructurally, the ice in this particular sample appears to have undergone some incipient recrystallization. A density of $0.827 \mathrm{Mg} \mathrm{m}^{-3}$ was measured, which, together with a bulk salinity of $9.8 \%$ measured at the in-situ temperature of the sample, $-2.8^{\circ} \mathrm{C}$, yields derived values for the brine and entrapped air volumes of 15.2 and $12.0 \%$, respectively. A mean gas bubble diameter of $0.24 \mathrm{~mm}$ was also measured, which is about four times smaller than the average diameter of crystals.

\section{Horizontal surfaces}

Samples M1 and M2. No sections, nor density, nor porosity data were obtained from these very thin samples $(0.6 \mathrm{~cm})$. Only bulk salinities, of about $25 \%$, were measured on these thin, soft, mushy deck-accreted samples.

Sample M8. This sample was obtained from 4.4$\mathrm{cm}$-thick ice accreted on the deck, 2-3 $\mathrm{m}$ port of the 5- 


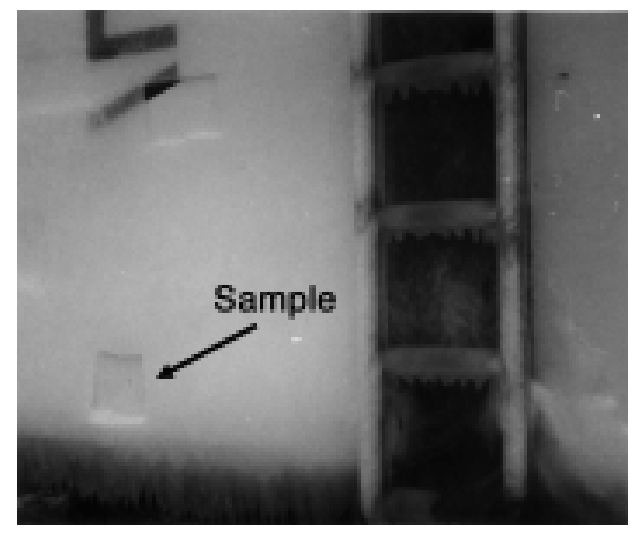

a. Sample location.

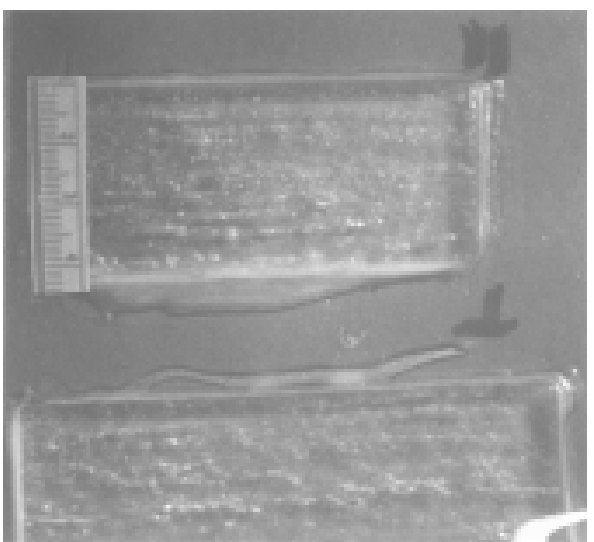

b. Thick sections photographed in natural light.

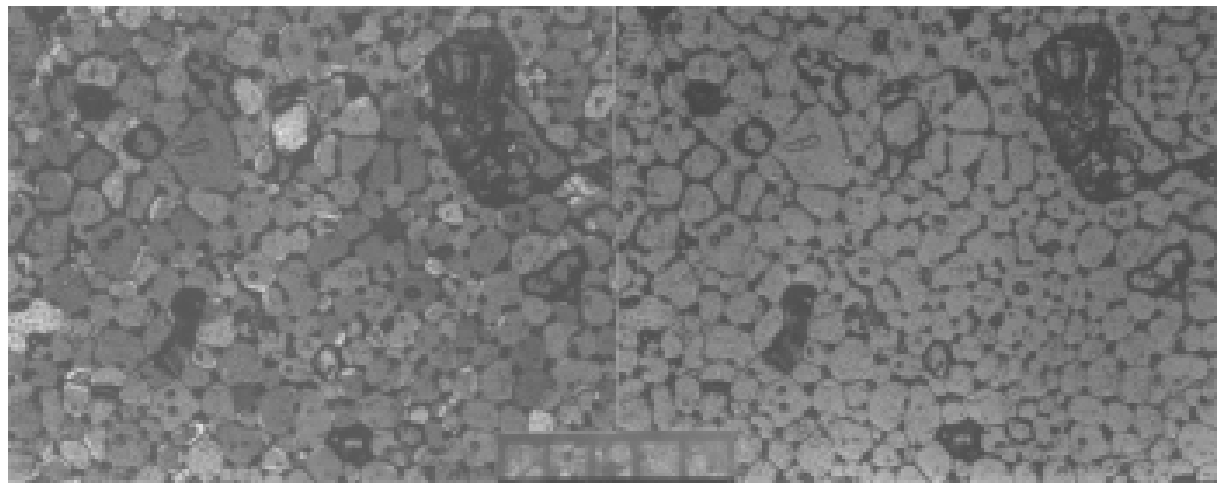

c. Thin sections photographed in natural light (right) and between crossed polarizers (left).

Figure 24. Sample M10, taken from the port bulkhead of the 5-in. gun housing, approximately $1 \mathrm{~m}$ above the deck (scales in millimeters). Thick sections suggest layering, and thin sections show a mixture of rounded and recrystallized ice grains. The dark structure in the upper right corner of the section is attributable to the coalescing of several brine pockets.

in. gun base (Fig. 26). The bulk salinity of this sample measured $16.2 \%$, which, together with the density of $0.868 \mathrm{Mg} \mathrm{m}^{-3}$, yielded entrapped air and brine volumes of 9.3 and $30.8 \%$ at a measured in-situ temperature of $-2.4^{\circ} \mathrm{C}$. The crystalline texture of this sample is characterized by rounded, somewhat elongated grains immersed in brine. Among deck samples, this particular sample exhibited the second largest mean crystal cross section $\left(1.33 \mathrm{~mm}^{2}\right)$ and the largest mean bubble diameter $(0.29 \mathrm{~mm})$.

Sample M13. This sample of deck icing (Fig. 27) was obtained from ice that had accreted to a thickness of $2.4 \mathrm{~cm}$, approximately $2 \mathrm{~m}$ in front of the $5-\mathrm{in}$. gun and about $0.5 \mathrm{~m}$ port of the windlass. Microstructurally, it consists of an intermixture of large, somewhat shapeless crystals with much smaller subrounded grains. The coarser crystals were among the largest measured in any sample collected on the cruise. They were certainly the largest observed in deck-accreted ice (Table 3). In coarsely crystalline deck samples, such as illustrated by this sample, layering is present but sometimes lacks continuity. A bulk salinity of $13.7 \%$ was measured, which, when used in conjunction with a density of 0.865 $\mathrm{Mg} \mathrm{m}^{-3}$ and an in-situ temperature of $-1.6^{\circ} \mathrm{C}$, gives values of 40.1 and $10.3 \%$ for the volumes of brine and air incorporated into the ice. A mean gas bubble diameter of $0.25 \mathrm{~mm}$ was also measured. 


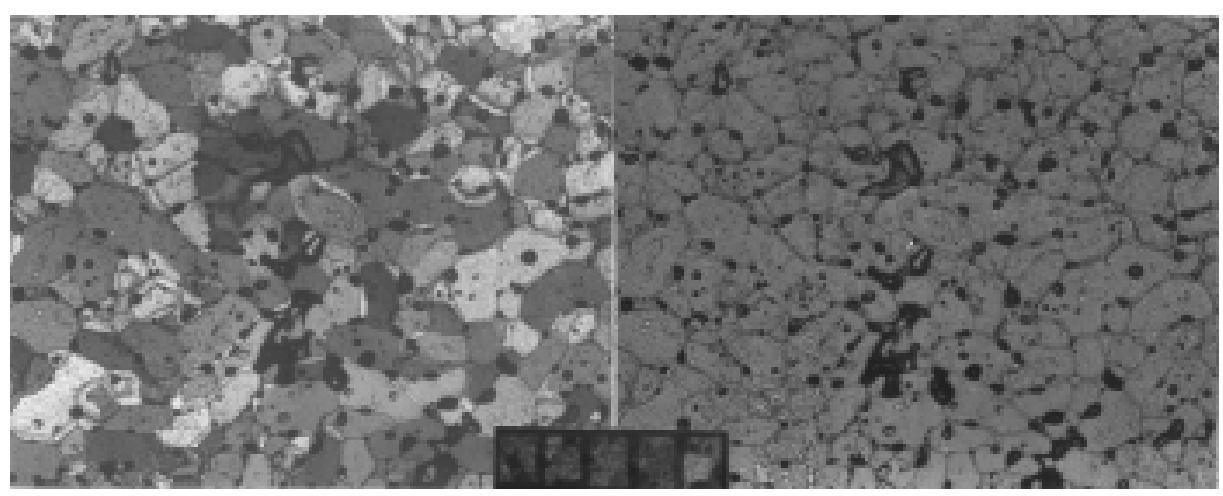

Figure 25. Sample M14, taken about $1.5 \mathrm{~m}$ above the deck surface from the front face of the 5-in. gun housing. No thick section or location photographs are available. Right to left are thin sections photographed in natural light and between crossed polarizers, respectively (scale in millimeters).

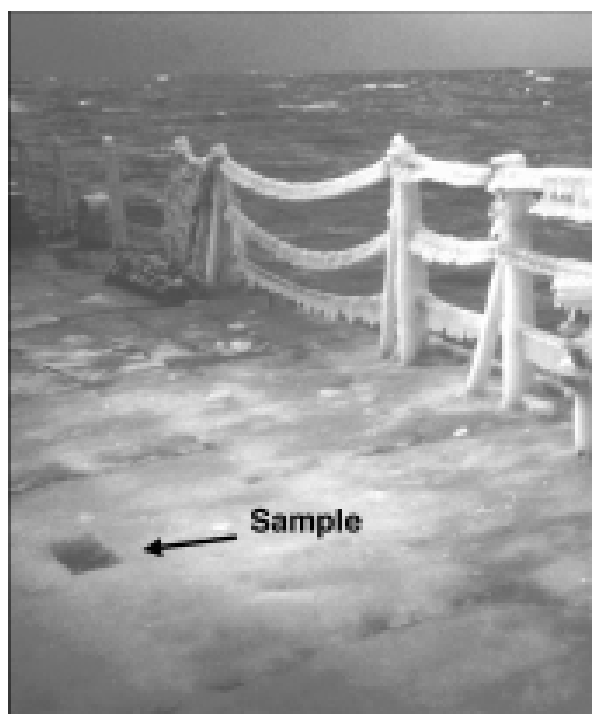

a. Sample location.

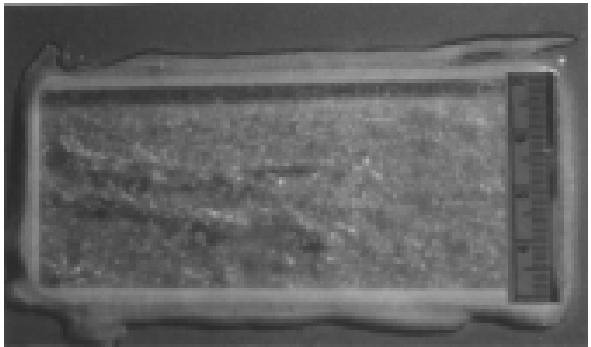

b. Thick section photographed in natural light.

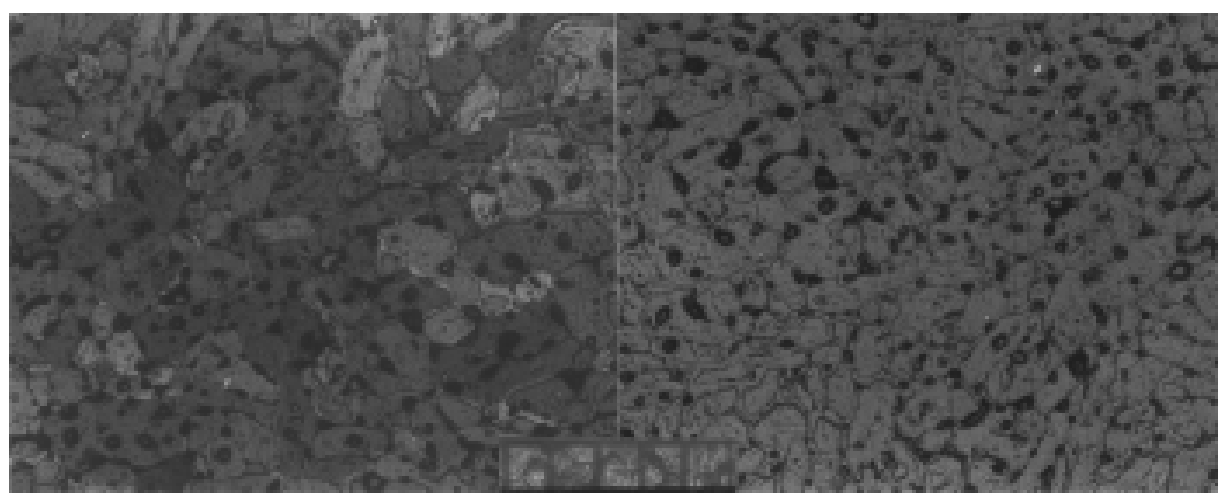

c. Horizontal thin sections photographed in natural light (right) and between crossed polarizers (left).

Figure 26. Sample M8, taken from the deck, 2-3 $\mathrm{m}$ to the port of the 5-in. gun base (scales in millimeters). Deck samples were typically wet because of poor drainage of water across the deck. 




a. Sample location.

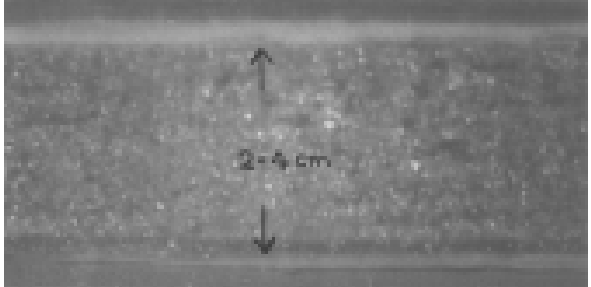

b. Thick section photographed in natural light.

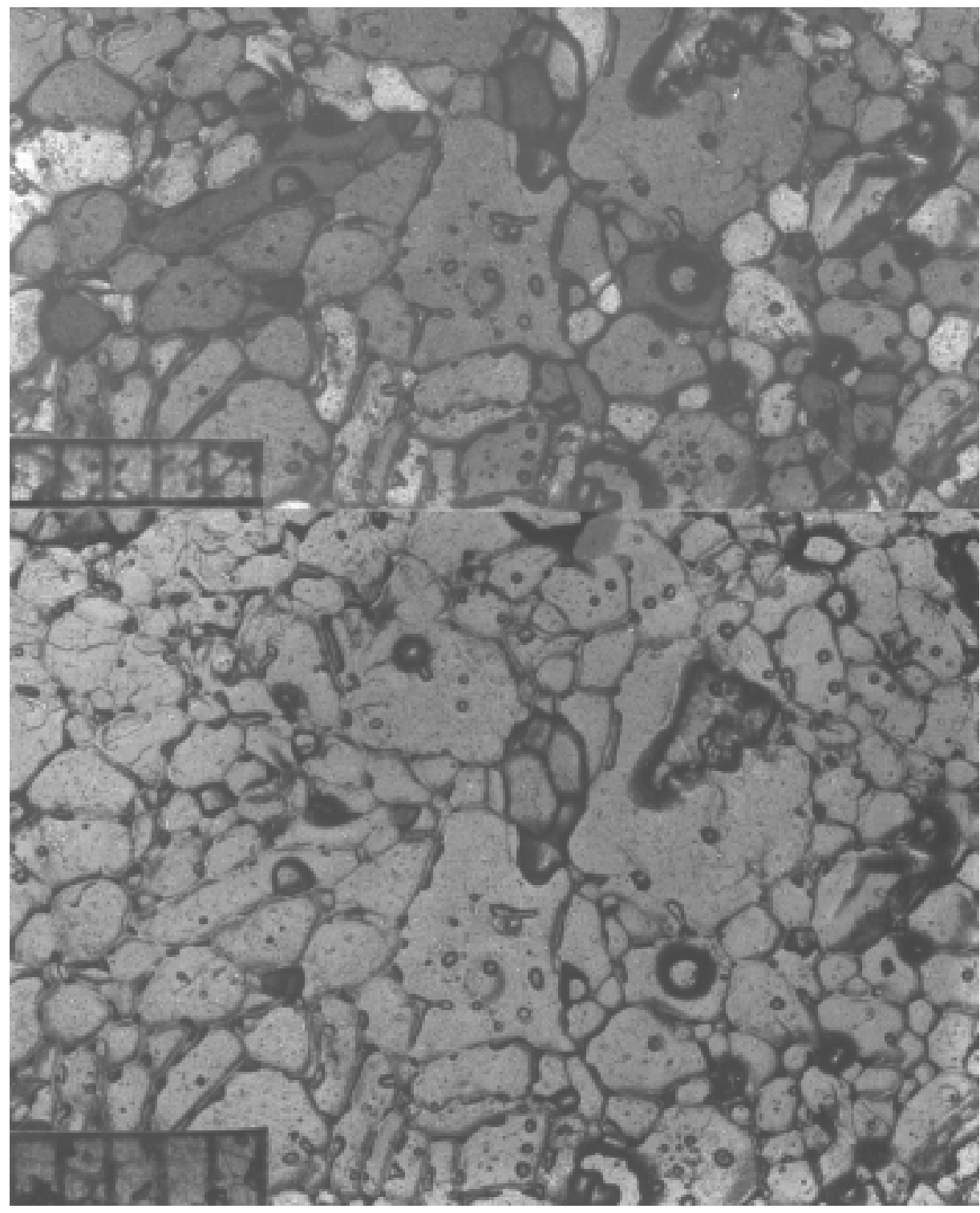

c. Thin sections photographed between crossed polarizers (top) and in natural light (bottom).

Figure 27. Sample M13, taken from the deck in warm weather, near $-3^{\circ} \mathrm{C}$ (scales in millimeters). Note the mixture of small crystals, and large, irregular crystals in the thin sections. Approximately $50 \%$ of the sample consisted of pores filled with brine or air. 


\section{Icicles}

Sample M4. This was a lifeline sample—only bulk salinity $(16.7 \%$ ) was obtained for this (Table 2$)$.

Sample M11. This example of an icicle formed on a polypropylene lifeline was collected at a location forward of the 5-in. gun mount immediately port of the windlass (Fig. 28 and 29). The sample was about $6 \mathrm{~cm}$ long and $8 \mathrm{~cm}$ wide, and was hanging down and away from the relative wind (winds were from the port bow). Brine was dripping from the icicle, and it was very firm and difficult to remove from the polypropylene lifeline. A vertical section, cut longitudinally through the length of the icicle, is shown here photographed between crossed polarizers (Fig. 28). The microstructure shown in Figure 29 is characterized by grains elongated longitudinally down the length of the icicle, occasionally consisting of crystals measuring several millimeters in length. An intermixing of these elongate grains with smaller rounded grains is also featured in this section. A bulk salinity of $11.8 \%$ was measured. The thin section gives the impression of grains substantially immersed in brine.

Sample M12. This sample was retrieved from one of many icicles dripping from the bottom of the 5-in. gun mount (Fig. 30). The icicle sample appears to be two or more merged icicles. Brine was dripping from the icicles as they were removed. Crystals appear to radiate from two nodes, assumed to be drip tubes, and swirl counterclockwise around the left drip tube but not around the right tube. Crystals also appear to radiate outward from each drip tube outside of the swirl zone. A particular feature of the vertical section microstructure of this icicle is the incorporation of large millimeter-sized grains among much smaller grains, as is clearly demonstrated in Figure 30. These two contrasting types of crystals were analyzed separately for grain size; results are presented in Table 3. A bulk salinity of $14.2 \%$ was measured on one of the icicles.

\section{CONCLUSIONS}

Ice accreted on horizontal and vertical surfaces of the USCGC Midgett ranged from densely packed ( 0.92 $\left.\mathrm{Mg} \mathrm{m}^{-3}\right)$ to loosely consolidated $\left(0.69 \mathrm{Mg} \mathrm{m}^{-3}\right)$. Texturally, accreted ice clearly resembled frazil ice, formed from the consolidation of freely nucleated ice crystals in sea water. This resemblance is also reflected in the ratios and magnitudes of incorporation of brine. Bulk salinities ranged from to 7 to $25.4 \%$ o compared to values of 6-7\% measured in normal sea ice. However, in frazil ice formed on the surface of the ocean, which frequently represents the initial mode of freezing of sea water, bulk salinities can exceed $10 \%$. The shapes of grains composing the crystalline structure of accreted ice ranged from rounded to polygonal. Our observation that ice formed during the initial stages of accretion frequently displayed a polygonal crystalline structure can probably be attributed to thermally driven modification of the original microstructure, caused possibly by heat leaking from the interior of the vessel. This process is generally manifested by the straightening of crystal boundaries, and by the formation of triple junctions intersecting at equilibrium angles of approximately $120^{\circ}$, as observed in thin sections.

We noticed no trend towards a preferred orientation of crystallographic c-axes, either in freshly accreted ice or its thermally modified (recrystallized) variant. Mean grain dimensions ranged from a minimum value of 0.56 $\mathrm{mm}$ to a maximum of $1.15 \mathrm{~mm}$. The only exceptions were one deck sample accreted in very warm weather (M13) and icicle type ice, where the dimensions of the crystals often exceeded several millimeters and where we commonly observed dimensional orientation (elongation of crystals in a preferred direction) in the microstructure. Excluding this one deck sample and the icicles, we found that the mean dimension of crystals accreted on both horizontal and vertical surfaces of the USCGC Midgett were similar to those measured by Tabata et al. (1963), but generally much larger than those derived from three-dimensional measurements of crystals reported by Golubev (1972). Golubev also reported significant levels of preferred orientation of the crystallographic c-axes. We did not, nor does this appear to be the case of observations of c-axis orientation in accreted ice examined by Tabata et al. (1963).

Estimates of brine volume and entrapped air content derived from measurements of the salinity, density, and in-situ temperature of samples, in conjunction with the equations of Cox and Weeks (1983), indicated widely ranging values, as expected in view of the wide ranging values of density, salinity, and temperature.

Though the icing rates experienced on the USCGC Midgett were low, and ice thicknesses were small, useful measurements were made. Ice thickness was greater on decks than on bulkheads, with an approximately 1.25:1 ratio between deck and bulkhead ice thickness. If ice density on bulkheads and decks is also accounted for, the ratio of mass per unit area increases the ratio to 1.4:1 because the density of the ice on the decks was larger than that on the bulkheads. This ratio has implications for modeling superstructure icing, because higher levels on ships, where center of gravity is most affected by ice, are dominated by bulkheads. Ice on horizontal surfaces (deck and hatch covers) also produced fewer and smaller inclusions than did ice on vertical surfaces (bulkheads). 


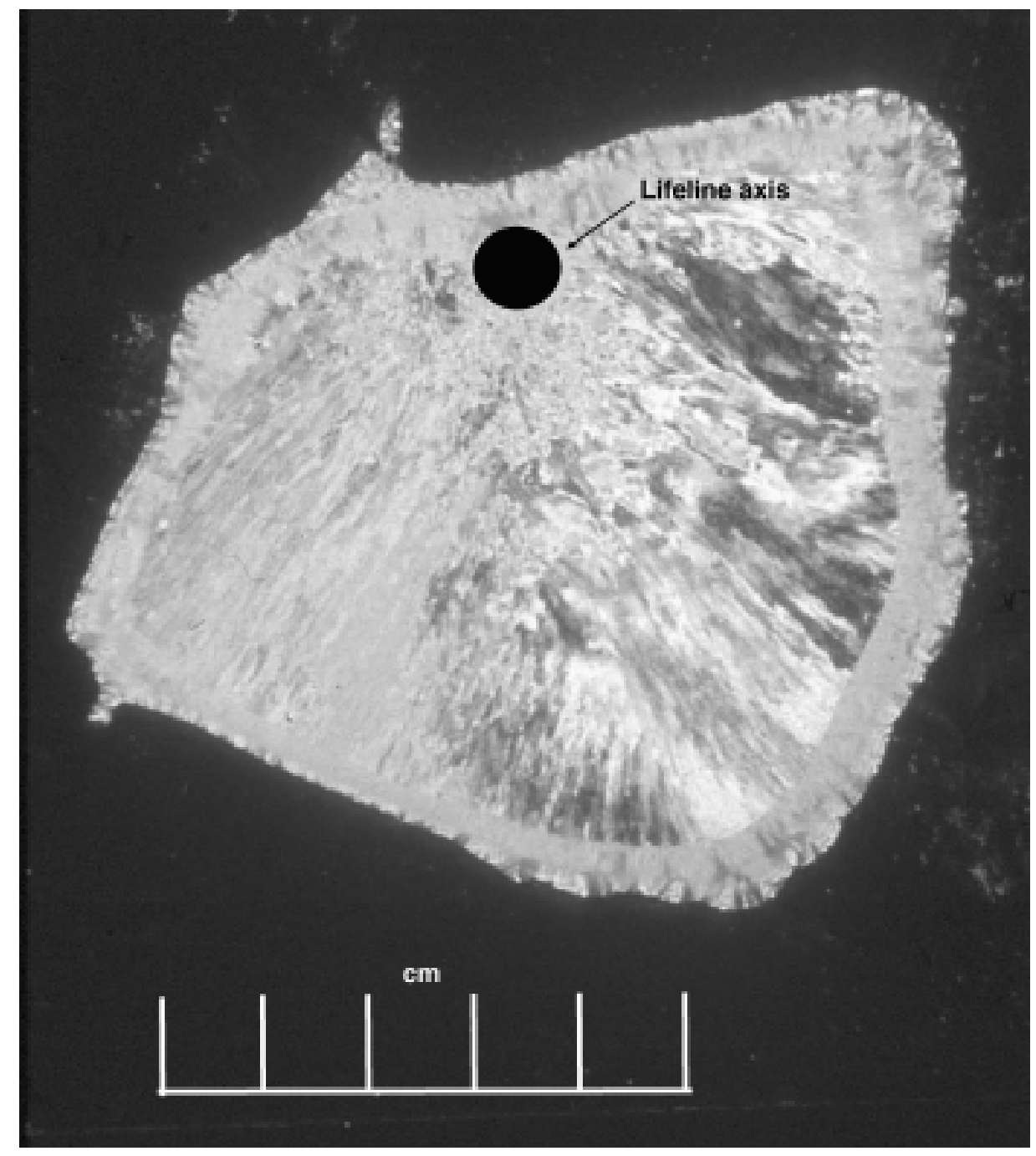

Figure 28. Vertical section of icicle, sample M11, photographed between crossed polarizers. Note the small, round ice crystals near the lifeline, and the elongated crystals radiating away from it. The outermost layer around the sample is an artifact of mounting the sample on a glass slide. 


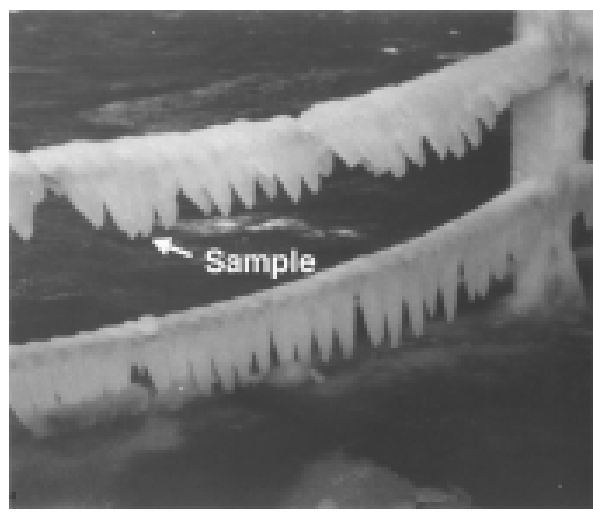

a. Sample location.

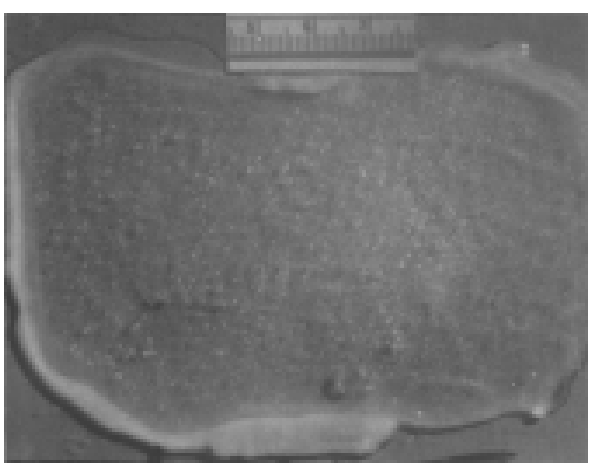

b. Horizontal thick section through the icicle photographed in natural light.



c. Vertical cross section with a mixture of rounded and elongated crystals as observed between crossed polarizers.

Figure 29. Sample M11, taken from an icicle removed from the left end of the upper lifeline shown in Figure 29a (scales in millimeters). 


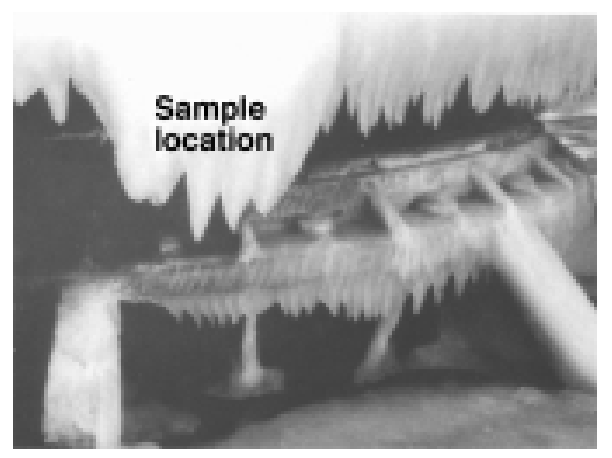

a. Sample location.

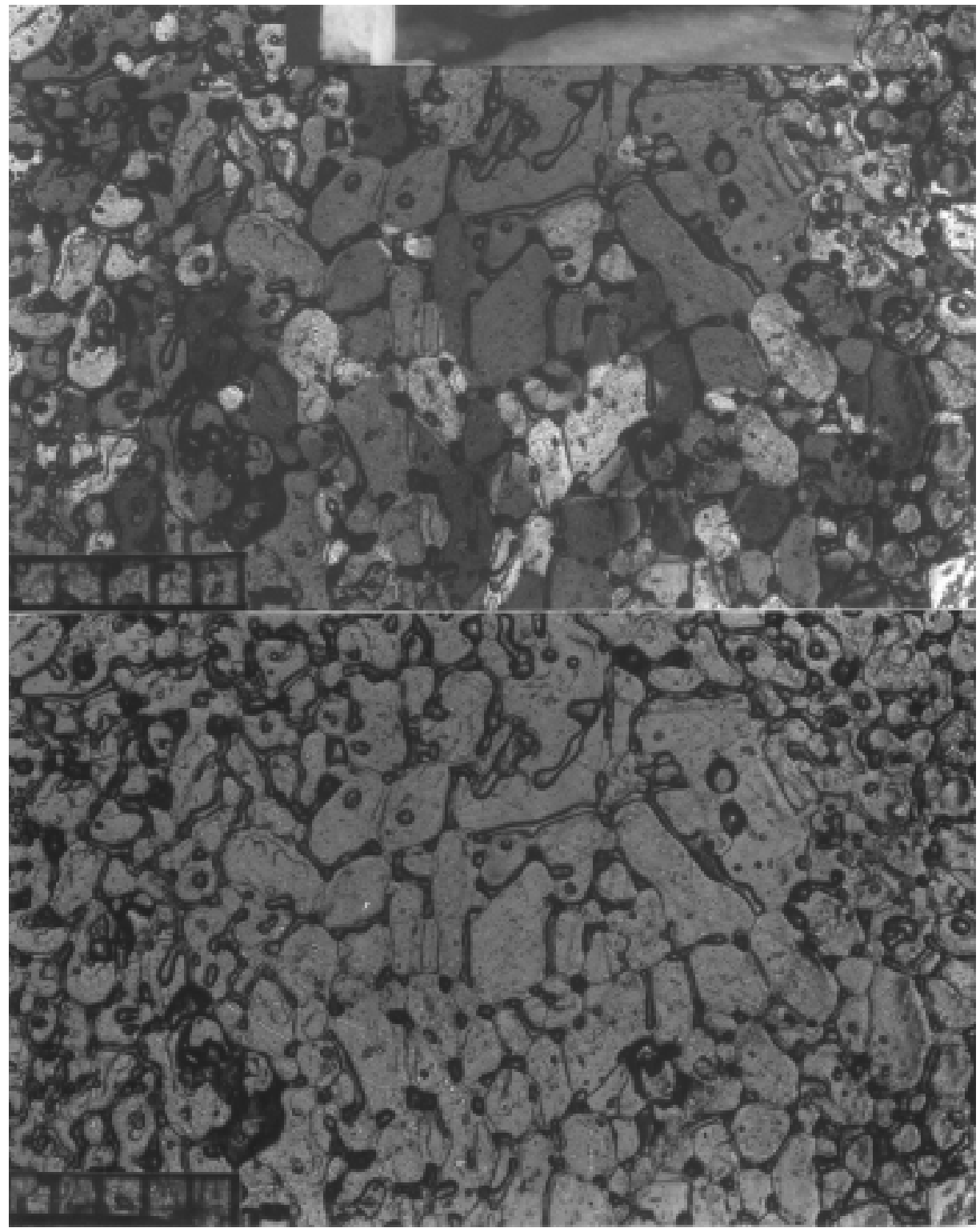

b. Thin sections photographed between crossed polarizers (top) and in natural light (bottom).

Figure 30. Sample M12, taken from icicles hanging from the port side base of the 5-in. gun housing (scales in millimeters). 
Structure analysis of ice accreted around a polypropylene life line showed the largest ice crystals observed aboard the cutter. Small, rounded, randomly oriented crystals dominated the ice mass immediately around the wire. Thereafter, long crystals grew radially to the outer edge of the elongated ice mass. The saline icicle externally resembles a freshwater icicle, as described by Laudise and Barns (1979), and the internal structure appears similar to the crystal structure in freshwater glaze ice around hay stalks, where crystal growth is perpendicular to and radially oriented around the stalk (Ackley and Itagaki 1974). In the case of glaze, heat is initially lost to the accretion surface, but eventually heat flows into the atmosphere as ice thickness increases. Crystal growth is thus promoted in the direction of cooling, down the temperature gradient, and towards the atmosphere.

Saline icicles actively grew below the 5 -in. gun housing. Externally, they exhibit several features of freshwater icicles, including horizontal surface ribbing and pendant drops (Geer 1981). Internally, they have features of freshwater icicles, and saline subaqueous stalactites (Weeks and Ackley 1982, Perovich et al. 1995). Crystal growth is radial away from and orthogonal to the long axis of the icicle, similar to some freshwater icicles (Laudise and Barns 1979). However, it is also similar in some respects to stalactites that form under sources of cold, highly saline brine, such as thick, young ice (Perovich et al. 1995). In the latter case, cold brine flows through the stalactites within tortuous channels up to several centimeters in diameter. The channel is commonly frazil lined, with columnar crystals growing radially into the surrounding warmer water. The icicle brine tubes on the cutter were surrounded by ice transitioning from frazil to elongated crystals that were approaching columnar in appearance and also growing radially. Processes that produce saline icicles have been modeled (Makkonen 1988, Lozowski and Szilder, in press), but detailed comparisons have not been made between stalactite and saline icicle processes.

Ice properties on the USCGC Midgett were generally similar to those observed by the Soviets on trawlers. Salinity was generally lower on vertical surfaces than on horizontal surfaces because of brine drainage. Ice density fell within the range of observations by the Soviets, and was somewhat lower on vertical surfaces than on horizontal surfaces. Following this ice salinity pattern, the percentage of ice pores filled with brine in the February event, and with one exception in the March event, was greater on horizontal than on vertical surfaces as calculated by the Cox and Weeks (1983) equations.

\section{LITERATURE CITED}

Ackley, S. (1985) Sea spray icing: A review of current models. In Proceedings, 1985 U.S. Navy Symposium on Arctic/Cold Weather Operations of Surface Ships. Washington, D.C.: Deputy Chief of Naval Operations for Surface Warfare.

Ackley, S., and K. Itagaki (1974) Crystal structure of a natural freezing rain accretion. Weather, 29(5): 189192.

Ahlmann, H., and F. Droessler (1949) Glacier ice crystal measurements, Kebnekajse, Sweden. Journal of Glaciology, 1(5): 268-274.

Borisenkov, Ye., and V. Panov (1972) Basic results and prospects of research on hydrometeorological conditions of shipboard icing. In Issledovaniye Fizicheskov Prirody Obledeneniya Sudov, Leningrad. USA Cold Regions Research and Engineering Laboratory, Draft Translation TL411, 1974, p. 1-30.

Brown, R., and P. Roebber (1985) The ice accretion problem in Canadian waters related to offshore energy and transportation. Canadian Atmospheric Environment Service, AES Report No. 85-13, Downsview, Ontario. Cox, G., and W. Weeks (1983) Equations for determining the gas and brine volumes in sea-ice samples. Journal of Glaciology, 29: 306-316.

Frankenstein, G., and R. Garner (1967) Equations for determining the brine volume of sea ice from $-0.5^{\circ} \mathrm{C}$ to $-22.9^{\circ} \mathrm{C}$. Journal of Glaciology, 6(48): 943-944.

Gates, E., R. Narten, E. Lozowski, and L. Makkonen (1986) Marine icing and spongy ice. In Proceedings of the IAHR Symposium on Ice, Iowa City, Iowa, vol. 2, p. 153-163.

Geer, I. (1981) The not-so-ordinary icicle. Weatherwise, 34: 257-259.

Golubev, V. (1972) On the structure of ice formed during icing of ships (from the materials of expeditions research). In Issledovaniye Fizicheskov Prirody Obledeneniya Sudov, Leningrad. USA, Cold Regions Research and Engineering Laboratory, Draft Translation TL411, 1974, p. 108-116.

Gow, A. (1987) Restraints on thin section analysis of grain growth in unstrained polycrystalline ice. Journal de Physique, 48(3): 277-281.

Iwata, S. (1975) Ice accumulation on ships. In Contributions, Arctic Oil and Gas: Problems and Possibilities, 5th International Congress of the Fondation Francaise d'etudes Nordiques, 2-5 May 1973, Le Havre, France (J. Malaurie, Ed.). Volume 12, p. 363-386.

Jorgensen, T. (1982) Influence of ice accretion on activity in the northern part of the Norwegian conti- 
nental shelf. Offshore Technology Testing and Research Report No. F82016, Continental Shelf Institute, Norwegian Hydrodynamic Laboratories, Trondheim, Norway.

Kultashev, Ye., N. Malakhov, V. Panov, and M. Shmidt (1972) Spray icing of MFT and MFTF fishing vessels In Issledovaniye Fizicheskov Prirody Obledeneniya Sudov, Leningrad. USA Cold Regions research and Engineering Laboratory, Draft Translation TL411, 1974, p. 127-139.

Laudise, R., and R. Barns (1979) Are icicles single crystals? Journal of Crystal Growth, 46: 379-386.

Lozowski, E., and K. Szilder (in press) Computer simulations of marine ice accretion. Transactions of the Royal Society.

Makkonen, L. (1987) Salinity and growth rate of ice formed by sea spray. Cold Regions Science and Technology, 14: 163-171.

Makkonen, L. (1988) A model of icicle growth. Journal of Glaciology, 34: 64-70.

Mellor, M. (1983) Mechanical behavior of sea ice. USA Cold Regions Research and Engineering Laboratory, CRREL Report 83-1.

Ono, N. (1968) Studies of ice accumulation on ships, Part 2. Conditions of icing and ice accretion weights. Low Temperature Science (Teion Kagaku), Series A(22): 170-181. (Translated by E. Hope, National Research Council, Ottawa, Canada, Technical Translation 1319.) Panov, V. (1972) On calculation of water droplet temperature and ice salinity during spray icing of ships. In Investigation of the Physical Nature of Ship Icing, Issledovaniye Fizicheskov Prirody Obledeneniya Sudov, Leningrad. USA, Cold Regions Research and Engineering Laboratory, Draft Translation TL411, 1974, p. 4248.

Perovich, D., J. Richter-Menge, and J. Morison (1995) Formation and morphology of ice stalactites observed under deforming lead ice. Journal of Glaciology, 41(138): 305-312.

Ryerson, C. (1991) Ship superstructure icing climatology of coastal eastern North America. In Proceedings of the Forty-Eighth Annual Eastern Snow Conference, Guelph, Ontario, p. 201-211.

Ryerson, C. (1995) Superstructure spray and ice accretion on a large U.S. Coast Guard Cutter. Atmospheric Research, 36: 321-337.

Ryerson, C., and A. Gow (in press) Crystalline structure of ship superstructure spray ice. Philosophical Transactions of the Royal Society: Mathematical, Physical and Engineering Sciences.
Ryerson, C., and P. Longo (1992) Ship superstructure icing: Data collection and instrument performance on the USCGC Midgett research cruise. USA Cold Regions Research and Engineering Laboratory, CRREL Report 92-23.

Ryerson, C., M. Walsh, and K. Knuth (1991) Spray and ice measurement instrumentation for ships. In Cold Regions Engineering, Proceedings of the Sixth International Specialty Conference, W. Lebanon, New Hampshire, p. 748-757.

Sapone, D. (1990) A sensitivity study of bow variants on the distribution of sea spray in regular head seas. Masters thesis, Massachusetts Institute of Technology (unpublished).

Schytt, V. (1958) Glaciology II. Inner structure of the ice shelf at Maudheim as shown by core drilling. Norwegian-British-Swedish Antarctic Expedition, 19491952, Scientific Results, Vol. IV C, Oslo, Norsk Polarinstitutt, 1958, p.113-148

Seligman, G. (1949) The growth of the glacier crystal. Journal of Glaciology, 1(5): 254-267.

Shellard, H. (1974) The meteorological aspects of ice accretion on ships. Marine Science Affairs Report no. 10 (WMO-No. 397), World Meteorological Organization, Geneva.

Smirnov, V. (1972) Conditions of ship icing and means of combating it (according to foreign data). In Issledovaniye Fizicheskov Prirody Obledeneniya Sudov, Leningrad. USA Cold Regions Research and Engineering Laboratory, Draft Translation TL411, 1974.

Stephenson, P. (1967) Some considerations of snow metamorphism in the Antarctic ice sheet in light of ice crystal studies. In Physics of Snow and Ice: International Conference on Low Temperature Science 1966, Proceedings (H. Oura, Ed.). Volume 1, Part 2. Sapporo Institute of Low Temperature Science, Hokkaido University, p. 725-740.

Tabata, T., S. Iwata, and N. Ono (1963) Studies of ice accumulation on ships, Part 1. Low Temperature Science (Teion Kagaku), Series A(21): 173-221. (Translated by E. Hope, National Research Council, Ottawa, Canada, Technical Translation 1318.)

Thomas III, W., and W. Lee (1987) Ship design atlas for cold weather regions. Report No. DTNRSRDC/ SPD-1212-01. David Taylor Ship Research and Development Center, Bethesda, Maryland.

Weeks, W., and S. Ackley (1982) The Growth, structure, and properties of sea ice. USA Cold Regions Research and Engineering Laboratory, CRREL Monograph 82-1. 


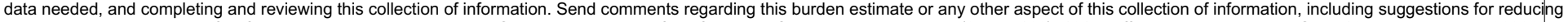

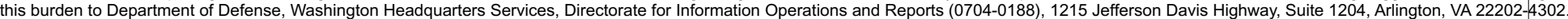

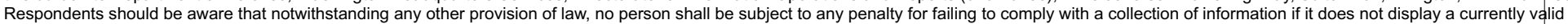
OMB control number. PLEASE DO NOT RETURN YOUR FORM TO THE ABOVE ADDRESS.

\begin{tabular}{l|l} 
OMB control number. PLEASE DO NOT RETURN YOUR FORM TO THE \\
\hline 1. REPORT DATE $(D D-M M-Y Y)$ & 2. REPORT TYPE
\end{tabular}

August 2000 Technical Report

4. TITLE AND SUBTITLE

Ship Superstructure Icing: Crystalline and Physical Properties 3. DATES COVERED (From - To)

a. CONTRACT NUMBER

5b. GRANT NUMBER

5c. PROGRAM ELEMENT NUMBER

6. AUTHOR(S)

Charles C. Ryerson and Anthony J. Gow

5d. PROJECT NUMBER

5e. TASK NUMBER

5f. WORK UNIT NUMBER

7. PERFORMING ORGANIZATION NAME(S) AND ADDRESS(ES)

U.S. Army Engineer Research and Development Center

Cold Regions Research and Engineering Laboratory

72 Lyme Road

ERDC/CRREL TR-00-11

Hanover, New Hampshire 03755-1290

8. PERFORMING ORGANIZATION REPORT NUMBER

9. SPONSORING/MONITORING AGENCY NAME(S) AND ADDRESS(ES)

10. SPONSOR / MONITOR'S ACRONYM(S)

Office of the Chief of Engineers

Washington, DC

U.S. Navy Office of Naval Research

Washington, DC

11. SPONSOR / MONITOR'S REPORT NUMBER(S)

\section{DISTRIBUTION / AVAILABILITY STATEMENT}

Approved for public release; distribution is unlimited.

Available from NTIS, Springfield, Virginia 22161.

13. SUPPLEMENTARY NOTES

\section{ABSTRACT}

In February and March 1990, measurements were made of superstructure ice on a United States Coast Guard cutter in the Bering Sea. Ice samples were removed from bulkheads, decks, and icicles during two icing events. Ice crystal measurements included crystal size, shape, orientation, brine pocket location, size and shape, internal layering, and air bubble sizes. Ice property measurements included salinity, density, and temperature, with computed estimates of air and brine volume. Texturally, accreted ice resembled frazil ice that forms from the consolidation of freely nucleated ice crystals in sea water. This resemblance is also reflected in bulk salinities, ranging from 7 to $24 \%$. The crystalline structure of accreted ice ranged from rounded to polygonal. Generally, rounded crystals would be expected for ice formed from sea spray droplets. The occurrence of polygonal crystals is attributed to thermally driven modification after deposition. No trend towards reorientation of crystallographic c-axes in either freshly accreted or thermally modified ice was observed. Mean crystal sizes ranged from 0.56 to $1.15 \mathrm{~mm}$, with even larger crystals in icicles. Ice salinity averaged about $12 \%$ on bulkheads and about $21 \%$ on decks. Ice densities ranged from 0.69 to $0.92 \mathrm{Mg} \mathrm{m}^{-3}$ and were generally higher on decks. Bulkhead ice had larger computed total porosity and air volume, and lower brine volume than deck ice. Samples taken from decks and bulkheads generally compared well with Russian and Japanese measurements.

\section{SUBJECT TERMS}

Crystal structure

Physical properties
Saline spray ice

Ship icing

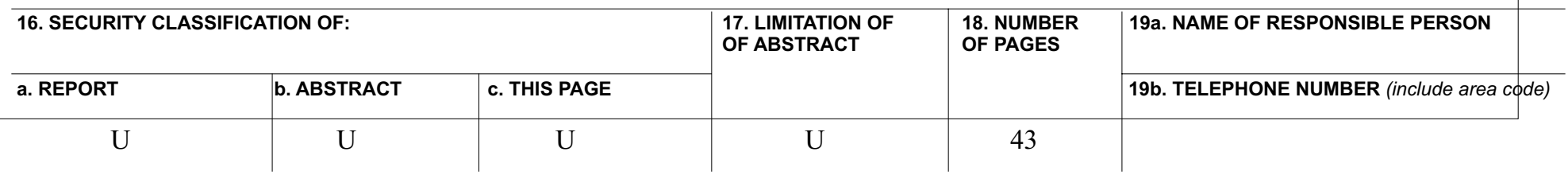

